\title{
Comparative analysis of airglow emissions in terrestrial planets, observed with VIRTIS-M instruments on board Rosetta and Venus Express
}

\author{
A. Migliorini ${ }^{\text {a,* }}$, G. Piccioni ${ }^{\text {a }}$, F. Capaccioni ${ }^{\text {a }}$, G. Filacchione ${ }^{\text {a }}$, F. Tosi ${ }^{\text {a }}$, J.-C. Gérard ${ }^{\mathrm{b}}$ \\ ${ }^{a}$ INAF-IAPS, Istituto di Astrofisica e Planetologia Spaziali, Via del Fosso del Cavaliere, 100, I-00133 Rome, Italy \\ ${ }^{\mathrm{b}}$ LPAP, Université de Liège, Allée du 6 Août, 17, Sart Tilman, B-4000 Liège, Belgium
}

\section{A R T I C L E I N F O}

\section{Article history:}

Received 20 December 2012

Revised 17 July 2013

Accepted 19 July 2013

Available online 30 July 2013

Keywords:

Terrestrial planets

Spectroscopy

Atmospheres, Composition

\begin{abstract}
A B S T R A C T
Airglow emissions are optimal processes to investigate the chemistry and dynamics in planetary atmospheres. In this study, we focus on the $\mathrm{O}_{2}$ and $\mathrm{OH}$ airglow emissions in Venus, Earth, and Mars atmospheres, which are controlled by chemical reactions common to the three planets. By studying these phenomena on Venus, Earth, and Mars using similar instruments, we are able to derive information about their photochemistry and the physical conditions of the atmospheres, but also to constrain the dynamics responsible for transport of atomic oxygen, ozone and other minor species.

After a review of the nightglow emissions observed in the Venus atmosphere, we analyze the $\mathrm{O}_{2}$ and $\mathrm{OH}$ airglow emissions in the Earth's atmosphere observed during the 3 swing-bys of our planet by the Rosetta spacecraft.

We also report the detection of the $\mathrm{O}_{2}$ nightglow emission in the Mars atmosphere, observed in February 2007 during the Rosetta fly-by of the planet. The airglow characteristics are in agreement with the measurements obtained from sensors on board Mars Express.
\end{abstract}

(c) 2013 Elsevier Inc. All rights reserved.

\section{Introduction}

Oxygen and hydroxyl airglow emissions are investigated in the atmospheres of Venus, Earth, and Mars, because they are used as tracers of atmospheric dynamics and photochemistry. The brightest oxygen airglow emission on all three terrestrial planets is associated with the (0-0) band of the $\mathrm{O}_{2}\left(\mathrm{a}^{1} \Delta_{\mathrm{g}}-\mathrm{X}^{3} \sum_{\mathrm{g}}^{-}\right)$transition at $1.27 \mu \mathrm{m}$ known as the Atmospheric Infrared system. Both dayglow and nightglow emissions at $1.27 \mu \mathrm{m}$ provide important information about the photochemistry and physical conditions of the atmosphere, and constrain the dynamics responsible of the transport of atomic oxygen.

Although the atmospheres of the terrestrial planets present some differences with respect to each other, common photochemical processes regulate the emission process.

The oxygen dayglow is produced by photolysis of ozone by solar UV radiation with $210 \mathrm{~nm}<\lambda<310 \mathrm{~nm}$, through reaction:

$\mathrm{O}_{3}+h v \rightarrow \mathrm{O}_{2}\left(\mathrm{a}^{1} \Delta_{\mathrm{g}}\right)+\mathrm{O}\left({ }^{1} \mathrm{D}\right)$,

\footnotetext{
* Corresponding author. Fax: +390645488 188.

E-mail addresses: Alessandra.Migliorini@iaps.inaf.it (A. Migliorini), Giuseppe. Piccioni@iaps.inaf.it (G. Piccioni), Fabrizio.Capaccioni@iaps.inaf.it (F. Capaccioni), Gianrico.Filacchione@iaps.inaf.it (G. Filacchione),Federico.Tosi@iaps.inaf.it (F. Tosi), JC.Gerard@ulg.ac.be (J.-C. Gérard).
}

while oxygen nightglow occurs through three-body recombination between atomic oxygen and another molecular species (indicated with $\mathrm{M}$ in the following formula), typically $\mathrm{CO}_{2}$, in the cases of Venus and Mars, or $\mathrm{N}_{2}$ or $\mathrm{O}_{2}$, in the Earth's case:

$\mathrm{O}+\mathrm{O}+\mathrm{M} \rightarrow \mathrm{O}_{2}\left(\mathrm{a}^{1} \Delta_{\mathrm{g}}\right)+\mathrm{M}$

The $\mathrm{O}_{2}\left(\mathrm{a}^{1} \Delta_{\mathrm{g}}\right)$ excited state can decay to the $\mathrm{X}^{3} \Sigma_{\mathrm{g}}$ ground state by emitting photons at $1.27 \mu \mathrm{m}$ for the $(0,0)$ band and at $1.58 \mu \mathrm{m}$ for the $(0,1)$ band with an efficiency of reaction equal to $98.4 \%$ and $1.6 \%$ respectively, or through quenching with $\mathrm{CO}_{2}$ molecules.

On the three planets, the oxygen atoms involved in reaction (b) are formed on the sunlit side from the photo-dissociation of the $\mathrm{CO}_{2}$ or $\mathrm{O}_{2}$ molecules by UV radiation at $\lambda \leqslant 200 \mathrm{~nm}$. For the Venus case, atoms are transported from the day to the night side by the upper atmospheric circulation, while for the Earth and Mars they are carried by the planetary rotation.

A revised scheme of excitation, quenching, and energy transfer processes in the $\mathrm{O}_{2}$ nightglow in the terrestrial planets is provided in Krasnopolsky (2011). The principal emissions in the visible and IR ranges are discussed. In the proposed scheme, the radiative lifetimes and quenching coefficients for some of $\mathrm{O}_{2}$ band systems are adjusted in order to fit the observed emissions. In addition, an upper limit for the $\mathrm{O}_{2}\left(\mathrm{~b}^{1} \sum_{\mathrm{g}}^{+}-\mathrm{X}^{3} \sum_{\mathrm{g}}^{-}\right)$Atmospheric band on Venus, not yet observed, is provided equal to $150 \mathrm{R}$ ( 1 Rayleigh is equal to 
an emission of $10^{6}$ photons $\mathrm{cm}^{-2} \mathrm{~s}^{-1}(4 \pi \mathrm{ster})^{-1}$ ) (Krasnopolsky, 2011).

For the Earth, the $\mathrm{O}_{2}$ infrared dayglow is important because it is very intense and allows investigation of the daytime ozone density, through indirect measurements, as reported in several observations (Noxon, 1982). The maximum of emission is observed at about $50 \mathrm{~km}$, with a secondary peak close to $85 \mathrm{~km}$. The intensity and peak position are highly variable with season, latitude, and solar zenith angle, as reported from rocket and ground-based observations (Winick et al., 1985). This reflects seasonal and latitudinal variations of the ozone concentration (Evans and Llewellyn, 1972; Noxon, 1972). The difference in altitude between the peak of the ozone density and the maximum emission at $1.27 \mu \mathrm{m}$ is a consequence of the collisional quenching of the $\mathrm{O}_{2}$ $\left({ }^{1} \Delta\right)$ molecule by $\mathrm{O}_{2}$ in the electronic ground state. Collisional deactivation of the oxygen upper state reduces the brightness of the lower part of the $\mathrm{O}_{2}\left({ }^{1} \Delta\right)$ emission profile, causing the emission maximum to be located above the peak of $\mathrm{O}_{3}$. The $1.27-\mu \mathrm{m}$ $\mathrm{O}_{2}$ nightglow is observed on average at $87 \mathrm{~km}$ height, though a double peaked structure is often present (Evans et al., 1972; Llewellyn and Solheim, 1978). The origin of this structure is still poorly understood, even though it seems to have a strict correlation with dynamics. In the terrestrial case, the $(0-1) \mathrm{O}_{2}$ band at $1.58 \mu \mathrm{m}$ is $40-146$ times less intense than the $(0-0)$ band, as determined from ground-based airglow observations (Pick et al., 1971; Winick et al., 1985), laboratory (Findlay, 1969; Noxon, 1967; Haslett and Fehsenfeld, 1969; Becker et al., 1971), or from models (Krupenie, 1972; Pick et al., 1971). However, it was the first to be observed from ground at twilight (Vallance Jones and Harrison, 1958). A more precise value for the band ratio was obtained by the recent Venus observations from Venus Express (Piccioni et al., 2009). A seasonal investigation of the $\mathrm{O}_{2}$ Atmospheric band centered at $760 \mathrm{~nm}$ was obtained with the High-Resolution Doppler Imager on the Upper Atmosphere Research Satellite (Hays et al., 2003). These observations confirm the longitudinal and latitudinal variability of the $\mathrm{O}_{2}$ emission brightness, which lasts one day or more, possibly attributed to tides. The observed features remain coherent on timescales of few hours, and they evolve significantly on about $24 \mathrm{~h}$.

In the martian case, the $\mathrm{O}_{2}$ dayglow has been largely investigated, also based on observations with instruments on board Mars Express mission, such as SPICAM (Spectroscopy for Investigation of Characteristics of the Atmosphere of Mars), PFS (Planetary Fourier Spectrometer), and OMEGA (Observatoire pour la Minéralogie, l'Eau, les Glaces et l'Activité). A seasonal investigation of the 1.27- $\mu \mathrm{m} \mathrm{O}_{2}$ emission using the SPICAM experiment reveals that the maximum of emission is observed in late winter-early spring at polar latitudes in both hemispheres, although it is stronger in the southern hemisphere (about $30 \mathrm{MR}, L_{S}=185-195^{\circ}$ ) than in the northern one (26 MR, $L_{s}=10-20^{\circ}$ ) (Fedorova et al., 2006). From OMEGA nadir data, the reported maxima are $31 \mathrm{MR}$ and $24 \mathrm{MR}$ for the southern and northern hemispheres respectively, as observed during the martian years \#27 and \#28 (Altieri et al., 2009). The emission is anti-correlated with water vapor abundance and solar illumination. During the winter season, the water vapor abundance decreases with latitude, while the ozone abundance increases, leading to stronger $\mathrm{O}_{2}$ emission. At the same time, solar illumination decreases pole-ward, thus reducing the $\mathrm{O}_{3}$ photodissociation rate and consequently the $\mathrm{O}_{2}$ emission intensity. At the limb, as observed with PFS, the $1.27-\mu \mathrm{m} \mathrm{O}_{2}$ emission shows a maximum between 20 and $30 \mathrm{~km}$ over the poles during equinoxes, while a second intense peak is also observed during spring equinox (Geminale et al., 2012). For this reason, the oxygen airglow emission on Mars has been used to study ozone abundance mainly above $20 \mathrm{~km}$, where quenching by $\mathrm{CO}_{2}$ becomes less important (Ball et al., 1993; Ball and Hancock, 1995).
Only recently, the $\mathrm{O}_{2}$ Mars nightglow emission at $1.27-\mu \mathrm{m}$ has been detected (Bertaux et al., 2012; Clancy et al., 2012; Fedorova et al., 2012). The emission is a consequence of the three-body recombination in downwelling air parcels of $\mathrm{O}$ atoms, produced on the dayside by $\mathrm{CO}_{2}$ photodissociation, as described above. From theoretical considerations, the emission is predicted at latitudes higher than $60^{\circ}$, and is not perfectly symmetric with respect to the North and South polar regions, as in the case of the $\mathrm{O}_{2}$ dayglow (Altieri et al., 2009). The reported altitude of the slant emission is in the range $40-50 \mathrm{~km}$, with an intensity of 10-17 MR (Bertaux et al., 2012; Fedorova et al., 2012).

On Venus, $\mathrm{O}_{2}$ emissions in the visible (Krasnopolsky, 1983; Slanger et al., 2001, 2006; García-Muñoz et al., 2009a; Migliorini et al., 2013) and IR spectral ranges (Connes et al., 1979; Crisp et al., 1996; Ohtsuki et al., 2005, 2008a,b; Bailey et al., 2008; Piccioni et al., 2009) are the most studied. The (0-0) $\mathrm{O}_{2}$ band was observed for the first time from ground, both on the day (with and intensity of $1.5 \mathrm{MR}$ ) and on the night sides of the planet (with an intensity of $1.2 \mathrm{MR}$ ) by Connes et al. (1979). No other $\mathrm{O}_{2}$ dayglow evidence has been found so far. The nightglow (0-0) and the (01) $\mathrm{O}_{2}$ bands show a high variability in space and time, as highlighted in several studies (Connes et al., 1979; Crisp et al., 1996; Bougher and Borucki, 1994; Ohtsuki et al., 2005, 2008a,b; Piccioni et al., 2009). An extensive investigation of the (0-0) and (0-1) $\mathrm{O}_{2}$ bands observed simultaneously with VIRTIS spectrometer on board Venus Express allowed to derive the statistical distribution of the two emissions and their ratio (Piccioni et al., 2009). The (0-1) $\mathrm{O}_{2}$ band is on average $63 \pm 8$ times less intense than the (0-0) band, in terms of transition probability. On average, the (0-0) transition is maximum at an altitude of $97.4 \pm 2.5 \mathrm{~km}$. Considering the zonal distribution, a maximum vertical intensity of $1.2 \mathrm{MR}$ close to the anti-solar point is observed (Piccioni et al., 2009; Soret et al., 2012a).

Other important emissions were recently observed by VIRTIS on the Venus night side, such as the IR hydroxyl emissions (Piccioni et al., 2008; Gérard et al., 2010; Soret et al., 2010, 2012b; Migliorini et al., 2011), the IR nitric oxide (García-Muñoz et al., 2009b) and the oxygen emissions in the visible range (García-Muñoz et al., 2009a; Migliorini et al., 2013). Combined with the $\mathrm{O}_{2}$ nightglow emissions, all these species contribute to build up a 3-D picture of the night side of Venus, providing information about dynamics and photochemistry of the upper atmosphere. From the oxygen airglow observations, it was possible to infer the abundance of atomic oxygen, with a peak at about $105 \mathrm{~km}$ varying in the range $1-5 \times 10^{11} \mathrm{~cm}^{-3}$ (Gérard et al., 2009). Soret et al. (2012a) report a $\mathrm{O}$ hemispheric average density of $1.9 \times 10^{11} \mathrm{~cm}^{-3}$ at $106.1 \mathrm{~km}$ height, derived by combining $\mathrm{O}_{2}$ nadir and limb observations with VIRTIS.

Hydroxyl is a minor species widely investigated in the upper atmosphere of terrestrial planets. It has been observed on the Earth since 1950 (Meinel, 1950) and on the night side of Venus (Piccioni et al., 2008; Krasnopolsky, 2010), as stated above, but no indication about $\mathrm{OH}$ airglow in the Mars' atmosphere has been reported so far. An upper limit equal to $50 \mathrm{R}$ was set from the Mars-5 spacecraft data (Krasnopolsky and Krys'ko, 1976).

The so-called Bates-Nicolet mechanism (Bates and Nicolet, 1950 ) is invoked to explain the excited $\mathrm{OH}$ production with $v \leqslant 9$ :

$\mathrm{H}+\mathrm{O}_{3} \rightarrow \mathrm{OH}^{*}(v \leqslant 9)+\mathrm{O}_{2}$.

This reaction is effective for both the Earth and Venus. However, in the case of the Earth, the following reaction is also important:

$\mathrm{O}+\mathrm{HO}_{2} \rightarrow \mathrm{OH}^{*}+\mathrm{O}_{2}$.

On Earth, the $\mathrm{OH}$ emission generally exhibits a maximum located between 85 and $90 \mathrm{~km}$ height (Lowe et al., 1996; She and Lowe, 1998), which varies with season. The (8-3) OH emission, 
centered at $727.45 \mathrm{~nm}$, was largely studied by Liu et al. (2008) in order to derive its seasonal variability. The emission rate is maximum at $40^{\circ}$ latitude during winter on both hemispheres, but it suffers also from variability with latitude. The annual variability is stronger at morning, and it tends to disappear during night-time, at mid latitudes. On the contrary, the equatorial semi-annual variation with maxima at the equinoxes is weaker in the morning than in the evening.

The height profile is sometimes complex, with two maxima in the volume emission rate separated by several $\mathrm{km}$, as reported on WINDII measurements (Melo et al., 2000). The double peak is preferentially observed early in the night, at low-mid latitudes. The phenomenon is also more frequent during equinoxes. Gravity waves are likely to generate double-peaked profiles, while the structures with a large horizontal scale and long durations are more probably caused by temperature inversion layers (Melo et al., 2000).

Although the $\mathrm{OH}$ Meinel band emissions with $\Delta v>3$, which occur mainly in the visible, are weaker than those with $\Delta v=1,2$ in the infrared, the visible spectral range is the most studied in the Earth case, using rocket measurements. These observations were used to determine the altitude of $\mathrm{OH}$ emission in the Earth atmosphere, observed at about $87 \mathrm{~km}$ with a full width at half maximum (FWHM) of about $8 \mathrm{~km}$ (Heppner and Meredith, 1958; Lowe, 1960; Packer, 1961; Baker and Stair, 1988). However, it was found that the peak altitude also varies with the observed transitions (Rogers et al., 1973; Lopez-Moreno et al., 1987; McDade et al., 1987). A difference of 1-2 km, depending on the $v^{\prime}$ levels from 1 to 9, was explained considering the quenching and vibrational deactivation processes (McDade, 1991; Mende et al., 1993).

The $\mathrm{OH}$ nightglow was unambiguously identified also in the Venus nightside atmosphere, using the VIRTIS (Visible and InfraRed Thermal Imaging Spectrometer) instrument onboard Venus-Express (Piccioni et al., 2008). The (1-0) band at $2.80 \mu \mathrm{m}$, the (2-1) at $2.94 \mu \mathrm{m}$, and the $(2-0)$ at $1.43 \mu \mathrm{m}$ were observed, reporting a relative intensity of $880 \pm 90 \mathrm{kR}$ and $100 \pm 40 \mathrm{kR}$ for the integrated horizontal emission rates of the (1-0) and (2-0) bands, respectively, which become $16 \mathrm{kR}$ and $1.8 \mathrm{kR}$, assuming a factor of 55.4 to convert from limb to vertical direction.

The value of the mean intensity and altitude was investigated on a statistical basis by Soret et al. (2012b), reporting a slight difference in the mean peak altitudes for the $\mathrm{OH}(\Delta v=1)$ and $\mathrm{OH}(\Delta v=2)$. Limb data reveal a great deal of similarities between the $\mathrm{OH}$ Meinel and $\mathrm{O}_{2}\left(\mathrm{a}^{1} \Delta_{\mathrm{g}}-\mathrm{X}^{3} \Sigma\right)$ airglow emissions. Both emissions show their maximum close to the anti-solar point (Gérard et al., 2010; Migliorini et al., 2011), at an altitude of $95.3 \pm 3 \mathrm{~km}$ and $96 \pm 2.7 \mathrm{~km}$ respectively for $\mathrm{OH}$ and $\mathrm{O}_{2}$. According to Soret et al. (2010), the $\mathrm{OH}(\Delta v=1)$ presents on average an intensity value of $0.35 \mathrm{MR}$ along the line of sight, centered at $96.4 \pm 5 \mathrm{~km}$. In Migliorini et al. (2011), the zonal distribution of the $\mathrm{OH}(1-0)$ and $\mathrm{OH}(2-0)$ bands was shown to be in good agreement with the $\mathrm{O}_{2}$ airglow distribution (Piccioni et al., 2009; Gérard et al., 2008; Shakun et al., 2010). On the contrary, several local maxima and minima are observed in the meridional distribution of the $\mathrm{OH}$ emission, without a clear trend with latitude. A detailed analysis of simultaneous VIRTIS limb images of the $\mathrm{O}_{2}\left(\mathrm{a}^{1} \Delta_{\mathrm{g}}\right)$ and the $\mathrm{OH}(\Delta v=1)$ emissions showed that their 2-D morphology was very similar (Gérard et al., 2012). The authors argued that these similarities confirm that atomic oxygen is a common precursor to $\mathrm{O}_{2}\left(\mathrm{a}^{1} \Delta_{\mathrm{g}}\right)$ and ozone, which produces excited $\mathrm{OH}$ through reaction (c).

Krasnopolsky (2010) reported ground-based observations of the OH P1(4.5) line of the (1-0) band and the Q1(1.5) line of the (2-1) band in the Venus atmosphere. The intensities of the (1-0) and (21 ) bands, derived from these measurements, were respectively $7.2 \pm 1.8 \mathrm{kR}$ and $<1.4 \mathrm{kR}$ at $21: 30$, and $15.5 \pm 2 \mathrm{kR}$ and $4.7 \pm 1 \mathrm{kR}$ at $4: 00$. According to photochemical models, reaction (c) is the most likely source of excited $\mathrm{OH}$ in the Venus atmosphere, and hence the VIRTIS observations represent the first indirect measurement of $\mathrm{O}_{3}$ in the Venus nightside atmosphere. A refinement of the chemical processes acting in the upper atmosphere of Venus was proposed following these measurements (Krasnopolsky, 2010). According to the author, although $\mathrm{OH}$ is produced with $v \leqslant 9$ through the Bates-Nicolet mechanism, $\mathrm{OH}$ states with $v>2$ are strongly quenched by $\mathrm{CO}_{2}$. This would explain why only $\mathrm{OH}$ vibrational distribution with $v \leqslant 2$ have been observed in Venus atmosphere, while no $\mathrm{OH}$ emissions in the visible spectral range were observed. However, because of low ozone density on Venus, contribution from reaction (d) could not be excluded in producing excited $\mathrm{OH}$ on the planet. Later on, $\mathrm{O}_{3}$ was directly detected by the SPICAV (Spectroscopy for Investigation of Characteristics of the Atmosphere of Venus) experiment onboard Venus Express in the star occultation mode (Montmessin et al., 2011), confirming the theory that the Bates-Nicolet mechanism is the most efficient in producing excited $\mathrm{OH}$ in the Venus atmosphere. Considering reaction (c), a density product of $[\mathrm{H}]^{*}\left[\mathrm{O}_{3}\right]=4-9 \times 10^{15} \mathrm{~cm}^{-6}$ was inferred (Montmessin et al., 2011). This detection of ozone on the Venus night side prompted Soret et al. (2012b) to study the spectral distribution of the $\mathrm{OH}$ spectra observed with VIRTIS and the expected brightness. They showed that the single vibrational quantum jump model for quenching of $\mathrm{OH}^{*}$ by $\mathrm{CO}_{2}$ provides a good fit to the VIRTIS spectra and matches the observed limb intensity with $\mathrm{O}_{3}$ densities compatible with the SPICAV measurements.

In the present paper, we discuss results obtained with VIRTIS instruments on board Rosetta and Venus Express missions. A description of Rosetta and Venus Express missions and of the observations performed with VIRTIS instruments on board the two spacecraft is provided in Section 2. Subsequently, results obtained for the Earth and Mars with VIRTIS/Rosetta and a summary of the Venus results with VIRTIS/Venus Express are discussed in Section 3. Conclusions and a short comparison of the three terrestrial planets are provided in Section 4.

\section{Observations with VIRTIS-M}

\subsection{Rosetta mission}

Rosetta is the first European mission devoted to the close investigation of Solar System small bodies, using ten experiments on board the spacecraft (Schulz, 2009). It was launched on 2nd March 2004 and its trajectory towards the primary target, comet 67P/ Churyumov-Gerasimenko ( $C-G)$, is quite complex. The main scientific objectives of Rosetta mission deal with the study of the comet $67 \mathrm{P} / \mathrm{C}-\mathrm{G}$, with special emphasis on its nucleus and coma. However, gravity assist maneuvers with the Earth and Mars were performed during the cruise phase, as well as fly-bys with the main belt Asteroids (2867) Steins and (21) Lutetia. The investigation of the planetary airglow emissions is one of the goals foreseen for the mission during the Earth and Mars fly-bys. Finally, the spacecraft will start orbiting the comet in May 2014 and will closely escort it on its way to perihelion.

In the present work, we discuss results obtained by VIRTIS, the Visible and InfraRed Thermal Imaging Spectrometer, on board the spacecraft (Coradini et al., 2007). VIRTIS enables the investigation of surface properties of the comet and other bodies of the Solar System at hundreds of wavelengths simultaneously, in the visible and infrared spectral domains. It is the precursor of a series of imaging spectrometers, which are currently operating on other interplanetary missions, such as the VIRTIS instrument on board the ESA/Venus Express spacecraft and the VIR instrument aboard the NASA/Dawn mission.

VIRTIS is in turn made up of two spectrometers. VIRTIS-H, the high resolution channel, is an echelle spectrometer working in 
the $2-5 \mu \mathrm{m}$ spectral range, while VIRTIS-M, the mapping channel, is an imaging spectrometer operating in the $0.3-5.1 \mu \mathrm{m}$ range using two co-aligned detectors devoted to the VIS and IR ranges, respectively. The infrared region $(1.0-5.1 \mu \mathrm{m})$ is covered using 432 spectral bins with an average spectral sampling of $\sim 10 \mathrm{~nm}$ (i.e. the distance between the center of two consecutive spectral channels), while the visible channel covers the range $0.3-1.1 \mu \mathrm{m}$, with an average spectral sampling of $\sim 2 \mathrm{~nm}$.

VIRTIS-M allows one to build up a two-dimensional image for each of the 864 spectral bands, divided as 432 in the visible and 432 in the infrared parts respectively. Each image cube in the visible and/or infrared has a dimension of $432 \times N_{s} \times N_{l}$, where 432 is the number of spectral channels, $N_{l}$ (number of lines) depends on the length of the observation, while $N_{s}$ (number of samples) is the number of spatial pixels composing a line, usually equal to 256 . However, a spatial binning mode, by 2 or by 4 , is often applied in order to increase the signal-to-noise ratio (SNR), giving an $N_{s}$ value of 128 or 64 respectively. The field of view of each square-shaped pixel is 0.25 mrad wide, hence a 256 pixel $\times 256$ pixel image, obtained by using a scanning mirror, covers a $64 \mathrm{mrad} \times 64 \mathrm{mrad}$ field (which corresponds to 220 arcmin $\times 220$ arcmin).

Results obtained so far by VIRTIS/Rosetta at Mars and the asteroids have been reported in Coradini et al. (2010, 2011), Schulz et al. (2012), and Tosi et al. (2010, 2012). We now focus on VIRTIS-M data acquired during the four fly-bys, three with the Earth (the first occurred on 04-03-2005, the second on 13-11-2007, and the third
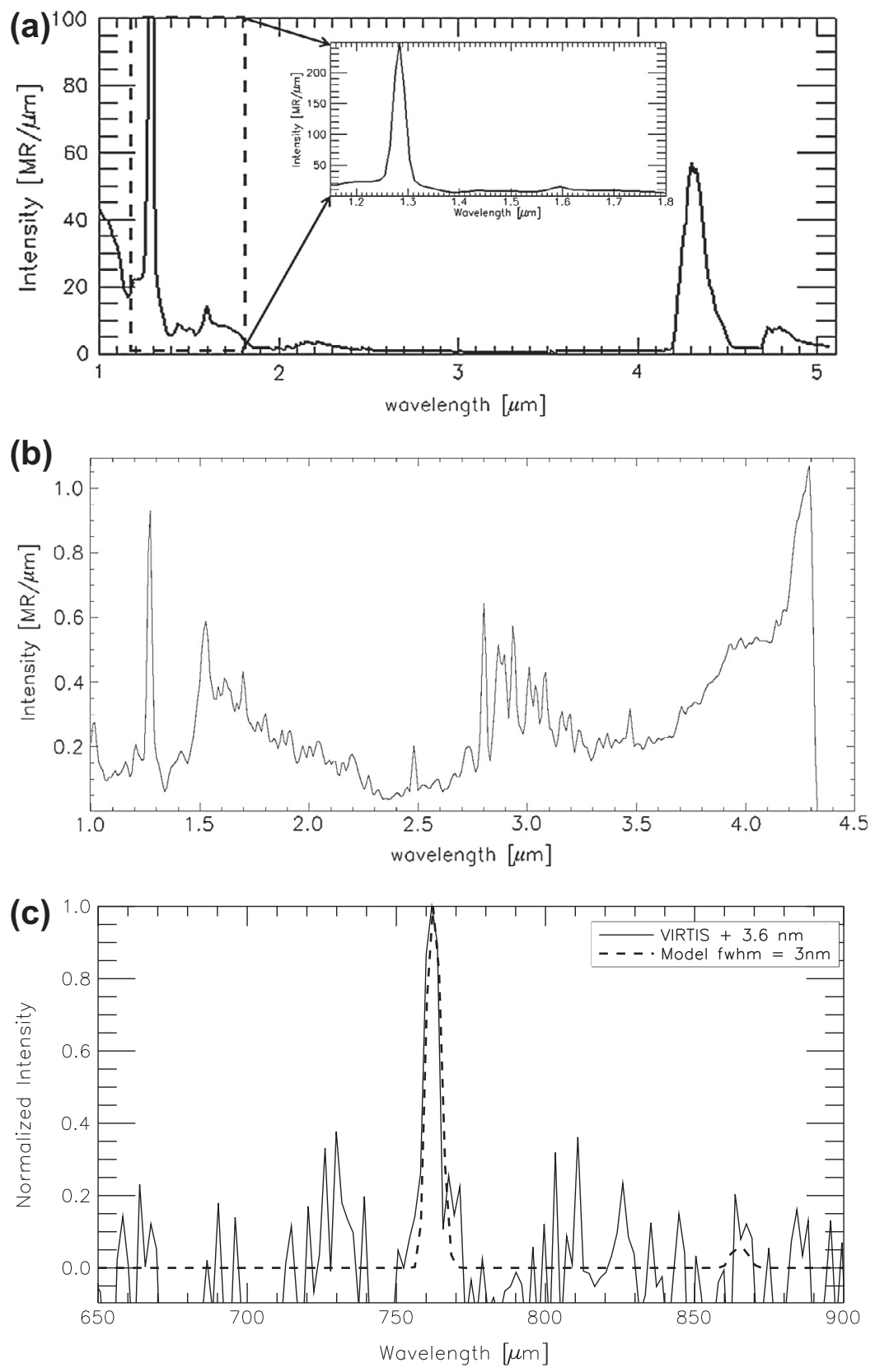

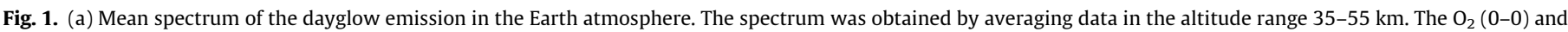

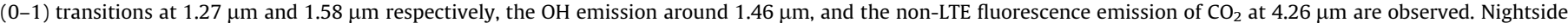

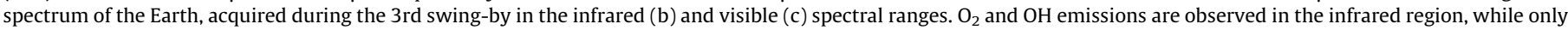
the $\mathrm{O}_{2}(0-0)$ Atmospheric band at $760 \mathrm{~nm}$ is observed in the visible. The visible spectrum is normalized at unity at $760 \mathrm{~nm}$. 
on 13-11-2009) and one with Mars (on 24-02-2007). In the following sections, the Rosetta observing geometry during the Earth and Mars fly-bys will be described.

\subsubsection{Earth fly-bys}

The first close encounter of Rosetta with the Earth, occurred on 4th March 2005, is not discussed here as the data acquired on this occasion are not suitable for airglow investigation, because of the low phase angle.

The second Earth swing-by (here after ESB\#2) occurred between 13 and 14 November 2007. In the approach phase, from a slant distance of 25,000-20,000 km, a sequence of scans of the limb was executed from a tangent altitude of about $300 \mathrm{~km}$ above the surface and downward, focusing on the dusk side of the planet. The acquired observations were optimized for the study of the non-LTE emissions of the $\mathrm{CO}_{2}$ and the $\mathrm{O}_{2}$ airglow. Fig. 1a shows the dayside spectrum of the Earth, observed at the limb with VIRTIS, in the altitude range $35-55 \mathrm{~km}$. The $\mathrm{O}_{2}$ emissions at $1.27 \mu \mathrm{m}$ and $1.58 \mu \mathrm{m}$, as well as the non-LTE $\mathrm{CO}_{2}$ emission at about $4.27 \mu \mathrm{m}$ can be recognized in the spectrum. Other fainter emissions can be identified in the spectrum, such as the $\mathrm{OH}$ emissions around $1.46 \mu \mathrm{m}$.

During the approach phase of the third Earth swing-by (here after ESB\#3), which occurred on 13 November 2009, a sequence of full-disk images of the night side of the planet was acquired from a distance spanning the range $228,000-240,000 \mathrm{~km}$. These data were not suitable for the $\mathrm{O}_{2}$ nightglow investigation, due to the low spatial resolution, hence they are not considered in this study. When the spacecraft was at a distance smaller than $55,000 \mathrm{~km}$, limb scans of the night side of the Earth were acquired, starting from $150 \mathrm{~km}$ above the surface. The spatial resolution ranged between 15 and $13 \mathrm{~km}$, and each scan lasted 2 min.

The mean infrared spectrum of the night side of the Earth atmosphere at $87-90 \mathrm{~km}$ is shown in Fig. $1 \mathrm{~b}$. The most intense emission is due to the $\mathrm{O}_{2}(0-0)$ transition centered at $1.27 \mu \mathrm{m}$. The $\mathrm{OH}(v=2)$ and $\mathrm{OH}(v=1)$ sequences at about $1.5 \mu \mathrm{m}$ and $2.81 \mu \mathrm{m}$ are also observed. The simultaneous observation in the visible is used to study the nightglow emission associated with the $\mathrm{O}_{2}\left(\mathrm{~b}^{1} \sum_{\mathrm{g}}^{+}-X^{3} \sum_{\mathrm{g}}^{-}\right)\left(0_{-}\right.$ 0 ) band, centered at $762 \mathrm{~nm}$. It results from the recombination of atomic oxygen with $\mathrm{O}_{2}$ following the two-step Barth mechanism (Greer et al., 1981; McDade et al., 1986; Murtagh et al., 1990). The mean spectrum is shown in Fig. 1c, normalized at unity at $760 \mathrm{~nm}$.

Subsequently, the spacecraft faced the dayside of the Earth, and starting from a distance of about $150 \mathrm{~km}$ above the surface, five scans of the dayside of the planet were acquired, with a spatial resolution of 11.5 or $7.5 \mathrm{~km}$ depending on the slant distance. While the spacecraft was departing from the Earth, a sequence of full disk images of the day side of the planet was performed with an onground spatial resolution of about $70 \mathrm{~km}$. During this phase, VIRTIS observed also the Moon to measure its thermal emission.

A summary of the data used in this study is reported in Table 1. It includes images acquired in the two mission periods, reporting the exposure time integration, and the slant distance.

\subsubsection{Mars fly-by}

The fly-by of Mars by Rosetta took place between 24 February 2007 18.14 UTC and 25 February 7.33 UTC, which corresponds to the martian year 28 (MY28) and solar longitude $L_{s}=189$. Most of the observations were performed in the eastern hemisphere of Mars, due to the fly-by geometry. A detailed description of VIRTIS observations achieved during the Mars fly-by is given in Coradini et al. (2010).

Daytime measurements in the range $1-3.5 \mu \mathrm{m}$ are dominated by the surface reflectance of incoming solar radiation (Fig. 2a).

Such reflectance is driven by the mineralogy and physical conditions of the soil. In this spectral range, absorption bands of the
Table 1

List of VIRTIS/Rosetta data used in the present work for the Earth investigation.

\begin{tabular}{|c|c|c|c|c|}
\hline Image name & $\begin{array}{l}\text { Observation } \\
\text { type }\end{array}$ & $\begin{array}{l}\text { Slant distance } \\
(\mathrm{km})\end{array}$ & $\begin{array}{l}\text { Latitude } \\
\text { (deg) }\end{array}$ & $\begin{array}{l}\text { Local } \\
\text { time }\end{array}$ \\
\hline \multicolumn{5}{|c|}{ Earth Swing-by \#2 } \\
\hline I1_0015605457 & Limb day side & $28,000-30,000$ & $58^{\circ} \mathrm{S}-72^{\circ} \mathrm{S}$ & $16.5-17$ \\
\hline I1_0015605802 & Limb day side & $24,000-27,000$ & $58^{\circ} \mathrm{S}-72^{\circ} \mathrm{S}$ & $16.2-17$ \\
\hline I1_0015606182 & Limb day side & $20,800-23,500$ & $58^{\circ} \mathrm{S}-70^{\circ} \mathrm{S}$ & $\begin{array}{l}15.3- \\
16.2\end{array}$ \\
\hline I1_0015606608 & Limb day side & $16,000-19,500$ & $57^{\circ} \mathrm{S}-66^{\circ} \mathrm{S}$ & $\begin{array}{l}14.5- \\
15.7\end{array}$ \\
\hline \multicolumn{5}{|c|}{ Earth Swing-by \#3 } \\
\hline I1_00216713355 & Limb night side & $53,000-60,000$ & $30^{\circ} \mathrm{N}-55^{\circ} \mathrm{N}$ & $0.7-2.7$ \\
\hline I1_00216714855 & Limb day side & $32,000-45,000$ & $37^{\circ} \mathrm{S}-60^{\circ} \mathrm{S}$ & $\begin{array}{l}14.3- \\
15.4\end{array}$ \\
\hline I1_00216716264 & Limb day side & $28,000-31,000$ & $36^{\circ} \mathrm{S}-53^{\circ} \mathrm{S}$ & $\begin{array}{l}14.6- \\
15.2\end{array}$ \\
\hline
\end{tabular}

main atmosphere component $\mathrm{CO}_{2}$ are present at 2.8, 2.0,1.6, and $1.42 \mu \mathrm{m}$. The $\mathrm{O}_{2}$ emission at $1.27 \mu \mathrm{m}$ is also visible, albeit embedded in the continuum due to the solar radiation. This emission is used to trace the ozone distribution, as explained before (Fedorova et al., 2006; Altieri et al., 2009).

In the nighttime data, the continuum in the $1.0-3.0 \mu \mathrm{m}$ region is negligible, and a very faint emission at about $1.27 \mu \mathrm{m}$ due to the $\mathrm{O}_{2}\left(\mathrm{a}^{1} \Delta_{\mathrm{g}}\right)(0-0)$ band is observed (Fig. $2 \mathrm{~b}$ ). This region was used for the oxygen nightglow detection in the martian atmosphere, observed for the first time with OMEGA/Mars Express (Bertaux et al., 2012), SPICAM/Mars Express (Fedorova et al., 2012), and CRISM (Clancy et al., 2012).

\subsection{Venus Express mission}

Venus Express, ESA's mission to Earth's nearest planetary neighbor, was launched from Baikonur's cosmodrome on 9 November 2005, and the spacecraft entered orbit around Venus in April 2006. The spacecraft revolves on a stable elliptical polar orbit with a period of $24 \mathrm{~h}$. The pericentre is at $250 \mathrm{~km}$ altitude above the North Pole, whereas the apocentre is at $66,000 \mathrm{~km}$ altitude from the South. The main objective of the mission is to study the complex dynamics and chemistry of the Venus' atmosphere, as well as its interactions with the surface, which provides clues about the surface's characteristics. It also studies the interplanetary environment (solar wind, plasma and magnetic field) to better understand the evolution of the planet (Svedhem et al., 2007).

The VIRTIS instrument onboard Venus Express is similar to the one included in the Rosetta payload. For instrument details, see description in Section 2.1.

We now discuss results obtained with VIRTIS/Rosetta data for the Earth and Mars, acquired during the four close encounters of the spacecraft with the planets. For the Venus case, we review results obtained with VIRTIS/Venus Express.

\section{Results}

\subsection{Earth airglow observed by VIRTIS/Rosetta}

The available data at limb acquired during the ESB\#2 were used to investigate the $\mathrm{O}_{2}$ dayglow, due to the ozone photo-dissociation through reaction (a). The mean spectrum of the Earth's dayglow is shown in Fig. 1a. Spectra in the altitude region between 35 and $55 \mathrm{~km}$ were selected and averaged. The most intense feature is due to the $\mathrm{O}_{2}$ emission at $1.27 \mu \mathrm{m}$. The $(0-1) \mathrm{O}_{2}$ band at $1.58 \mu \mathrm{m}$ is also observed, while the region $4.2-4.6 \mu \mathrm{m}$ is dominated by the $\mathrm{CO}_{2}$ non-LTE emission. From these data, the vertical profile of the $(0-0) \mathrm{O}_{2}$ band was derived (Fig. 3 ). 

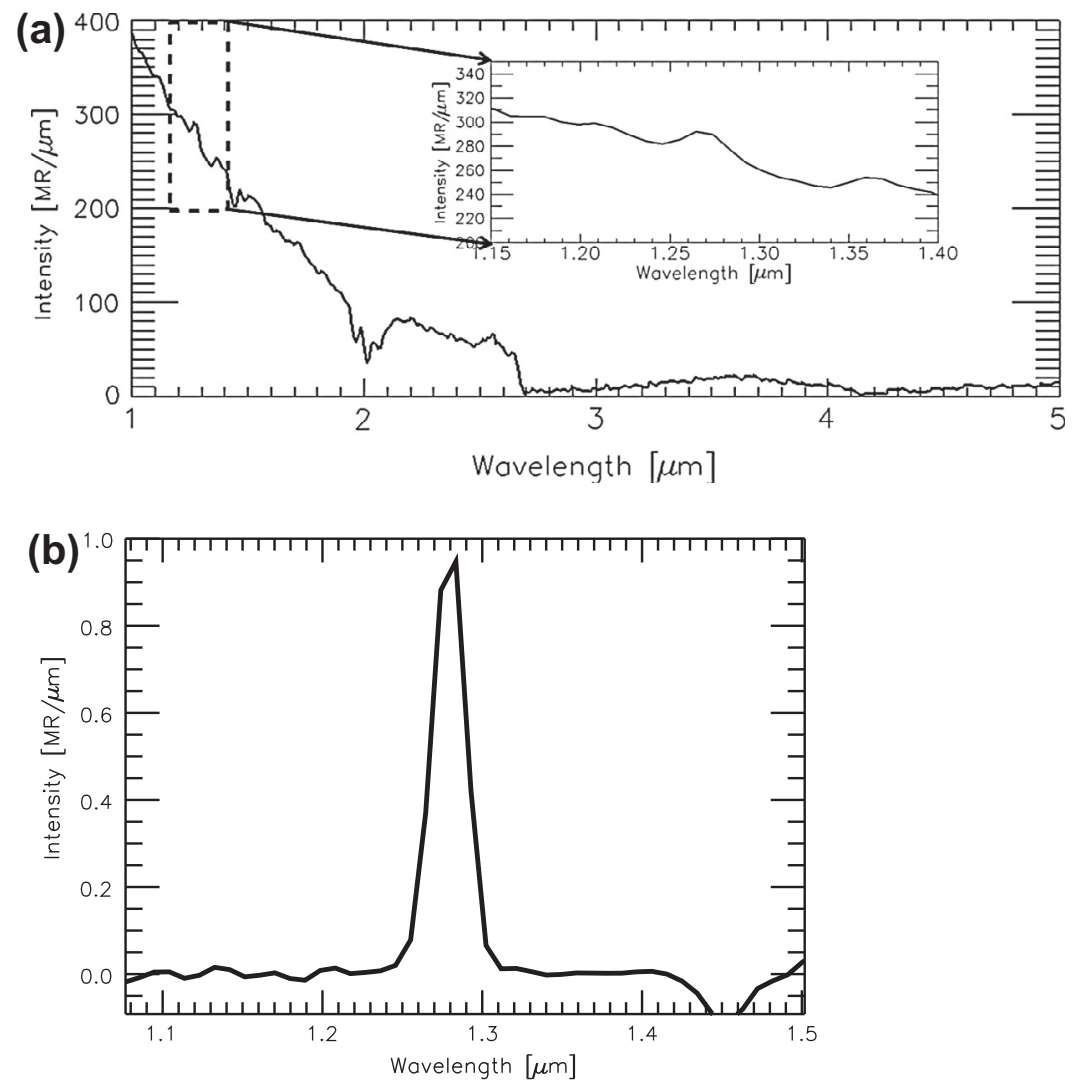

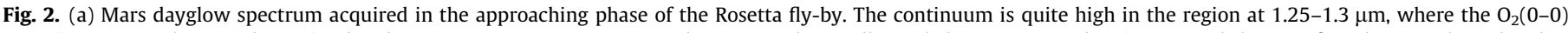

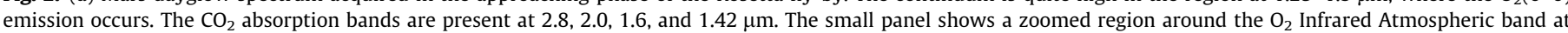
$1.27 \mu \mathrm{m}$. (b) Oxygen nightglow emission in the southern hemisphere of Mars. The mean spectrum refers to a local time close to midnight.

The peak altitude of the (0-0) $\mathrm{O}_{2}$ band at limb is found on average at $43.7 \pm 2 \mathrm{~km}$. A statistical investigation with respect to latitude was performed. The peak position is in good agreement with previous observations (Tarasick and Evans, 1993), while the intensity ranges between 44 and $250 \mathrm{MR}$, depending on latitude. The associated error is $5 \%$ of the peak intensity, evaluated for the VIRTIS spectral channel \#30 (which corresponds to the wavelength $1.27 \mu \mathrm{m}$ ) from the Noise Equivalent Spectral Radiance (NESR).

Despite some spurious features in the VIRTIS/Rosetta nightside spectrum of the Earth's atmosphere, the $(0-0) \mathrm{O}_{2}$ band at $1.27 \mu \mathrm{m}$, as well as the $\mathrm{OH}$ transitions with $\Delta v=1$, around $2.81 \mu \mathrm{m}$, and those with $\Delta v=2$, at $1.5-2.2 \mu \mathrm{m}$, were observed (see Fig. $1 \mathrm{~b}$ ). At $4.2 \mu \mathrm{m}$, the $\mathrm{CO}_{2}$ band can be recognized, although the signal is saturated above $4.3 \mu \mathrm{m}$. The spectrum is in good agreement with

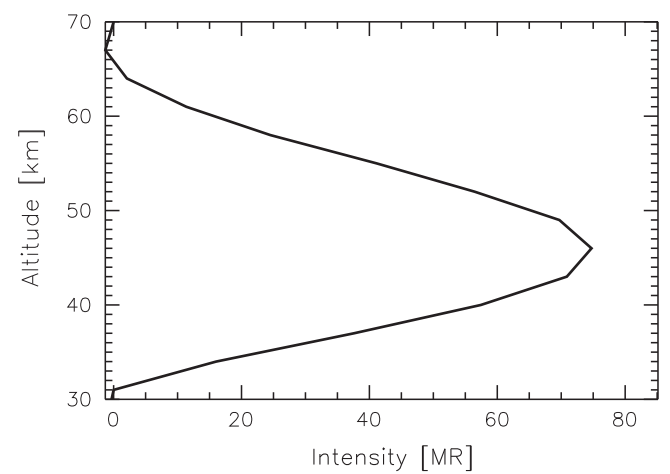

Fig. 3. Limb profile of the $\mathrm{O}_{2}$ dayglow emission in the Earth atmosphere. The maximum is observed in this case at about $46 \mathrm{~km}$, and the peak intensity is $75 \mathrm{MR}$. previous SPIRE rocket-borne experiment observations in the range 1.4-4.5 $\mu \mathrm{m}$ (Stair et al., 1985), although with a worse resolution with respect to VIRTIS.

In Fig. 4 we show a comparison between the average VIRTIS spectrum (black curve) and the ground-based spectrum (gray curve) acquired with ESO/ISAAC instrument (Rousselot et al. 2000). The two spectra are normalized at unity at the wavelength $1.5 \mu \mathrm{m}$, since the wavelength calibration and the spectrum shape are the real purpose of this comparison, as discussed below, while the intensity of the bands will be modeled and presented in a future work.

Relative line intensities derived from the spectrum by Rousselot et al. (2000) were convolved to the VIRTIS resolution, using a FWHM of $20 \mathrm{~nm}$. This high-resolution spectrum is often used to

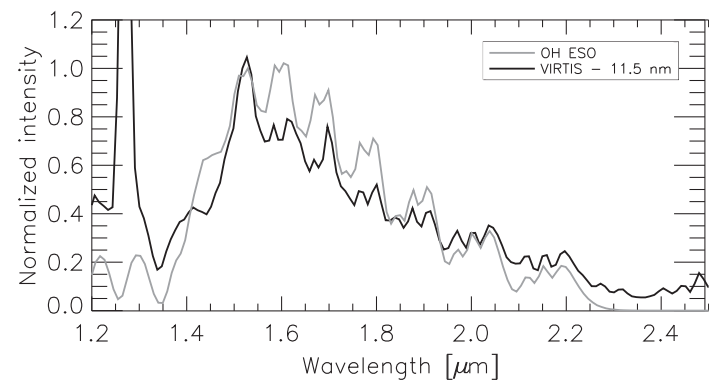

Fig. 4. Comparison between the VIRTIS nightside spectrum of the Earth and the high resolution spectrum (gray curve) acquired with ESO/ISAAC instrument in the $1.2-2.5 \mu \mathrm{m}$ range, convolved to the VIRTIS resolution. The VIRTIS spectrum is shifted by $11.5 \mathrm{~nm}$ towards shorter wavelengths to match the ground-based spectrum. 
spectrally calibrate in the near-infrared domain. We used this spectrum to refine the spectral calibration of VIRTIS, by evaluating the shift between each OH peak position in the current VIRTIS calibration and the correct position of the bands. The shifts vary in the range $7.5-18 \mathrm{~nm}$. The variation of the band wavelength shift can be attributed to uncertainty in the convolution process and to a wellknown VIRTIS grating distortion, described in Appendix A. These errors contribute in total to $30 \%$ of the observed shift. A mean shift equal to $11.5 \mathrm{~nm}$ towards the shorter wavelengths is finally applied to the original VIRTIS spectrum. The small distortion of the VIRTIS grating makes the required shift with respect to the higher resolution spectrum nonlinear, but rather variable with position along the slit. Moreover, an even effect is known to exist between the left and right side of the image. This effect is taken into account, and appropriately corrected by keeping separated the two parts of the image during the spectra selection, and by correcting each part separately. A detailed correction of instrumental aspects is described in Appendix A.

The agreement between the two spectra in Fig. 4 is satisfactory following application of the mean value shift.

In the visible spectral range, about 100 spectra are selected in the middle of the image and averaged. The low SNR is mainly due to the low sensitivity of the instrument and to the short exposure time (equal to $5.8 \mathrm{~s}$ ), which mainly affects the region at shorter wavelengths. At wavelengths longer than $800 \mathrm{~nm}$, the measured signal is affected by spurious effects caused by high orders coming from the infrared grating (Filacchione, 2006); hence caution must be adopted with the peaks observed in this spectral region. The $\mathrm{O}_{2}\left(\mathrm{~b}^{1} \sum_{\mathrm{g}}^{+}-\mathrm{X}^{3} \sum-\mathrm{g}\right)(0-0)$ Atmospheric band at $762 \mathrm{~nm}$, which is due to $\mathrm{O}_{2}$ recombination, is identified. It is modeled with a synthetic spectrum obtained by using the HITRAN database, and convolved to the VIRTIS resolution with a FWHM equal to $3 \mathrm{~nm}$. A shift of about $3.5 \mathrm{~nm}$ (almost corresponding to two spectral channels) towards shorter wavelengths is applied to the simulated spectrum in order to match the observed one. The (0-1) Atmospheric band centered at $864.5 \mathrm{~nm}$ is not observed in the VIRTIS spectrum, probably because of the low SNR. This observation is unique because for the first time the IR Atmospheric (at $1.27 \mu \mathrm{m}$ ) and Atmospheric (at $760 \mathrm{~nm}$ ) bands of $\mathrm{O}_{2}$ have been observed simultaneously. Although the observing geometry prevents observations of the full limb intensity distribution of emissions both in the visible and the infrared ranges, VIRTIS data point out that the IR emission is about 80100 times stronger than the visible one.

Despite the low spectral resolution of the VIRTIS observations in the visible and infrared ranges, the data analyzed here provide also the opportunity to spectrally calibrate the instrument in preparation to the incoming observations of the comet. The same procedure was not possible with other observations, such as those obtained during the Rosetta fly-bys of Asteroids (2867) Steins (on 5 September 2008) and (21) Lutetia (on 10 July 2010). These objects do not present narrow spectral features in the visible and infrared spectral regions to be used to this purpose, while the Atmospheric bands observed in the Earth atmosphere represent a good test. Further technical details about the correction of the spectral calibration response as function of the instrument's temperature are provided in Appendix A.

In addition, we verified the absence of the atomic oxygen green and red lines in the VIRTIS spectrum, which are usually observed in the Earth's atmosphere at $557.7 \mathrm{~nm}$ and $630 \mathrm{~nm}$, respectively. These transitions are not present in the VIRTIS mean spectrum because of the low instrument sensitivity at these wavelengths and because of the low SNR. In the spectral region of the two atomic oxygen emissions, we measured a radiance about 130 and 2500 times less intense than the radiance at $760 \mathrm{~nm}$, for the 557.7 and $630 \mathrm{~nm}$ wavelengths, respectively. This rules out the possibility of atomic oxygen lines detection in the available data.
ESB\#3 data were also used to investigate the vertical distribution of the nightglow emission. The $1.27-\mu \mathrm{m} \mathrm{O}_{2}$ nightglow emission is usually found to occur at about $87 \mathrm{~km}$ height, as reported in previous observations (Tarasick and Evans, 1993, and references therein). Because of the pointing geometry, no information below $85 \mathrm{~km}$ is available. However, a maximum in the emission is seen close to $86 \mathrm{~km}$ (not shown here), which does not contradict the previous observations, though this cannot be verified on the available data. Similarly, the intensity of the emission cannot be verified, because only a part of the emission, which extends for about $10 \mathrm{~km}$ around the peak maximum, is observed due to geometry restrictions. The estimated error for the nightglow emission is $10 \%$, considering the intensity at $1.27 \mu \mathrm{m}$. It is estimated as the ratio between the NESR and the radiance at the considered wavelength, as for the dayside.

\subsection{Mars airglow observed by VIRTIS/Rosetta}

During the Mars flyby of Rosetta (corresponding to $L_{S}=189$ ), images of the full disk of the planet were returned from a slant distance of about $200,000 \mathrm{~km}$. Because of the observing geometry, images of the dayside of Mars were acquired at limb during the approach phase, while the majority of the data refer to the full disk of the planet. For the nightside of the planet, only full disk images are available.

Data were divided in eight regions on the basis of local solar time (5-6 h, 6-12 h, 12-16 h, 18-20, 20-24 h) and latitude ranges (northern and southern hemispheres for the dayside, while only northern hemisphere for the nighttime), as listed in Table 2. Six regions refer to dayside of Mars (i.e. the local times 5-6 h, 6-12 h, $12-16 \mathrm{~h}$ for North and South), while two regions are selected as representative of the night side of the planet (local time ranges 18-20 $\mathrm{h}$ and 20-24 h) in the northern hemisphere.

For each region, a mean spectrum was calculated. We also evaluate the error affecting the measurements at $1.27 \mu \mathrm{m}$ (spectral channel \#30) through the ratio of the NESR with the average radiance of each region. The estimated errors are $6 \%$ and $20 \%$ for day and night side Mars observations, respectively.

On the dayside, solar radiation plays an important role in the measured spectra, as discussed in Section 2.1.2. To subtract this contribution, we modeled it as a line fitting the spectrum slope around the $\mathrm{O}_{2}(0-0)$ band at $1.27 \mu \mathrm{m}$. This method allows one to estimate at first order the continuum and subtract it, but its effectiveness is limited to the spectral region of interest. The average spectrum of each region and local times concerning the dayside of Mars is shown in Fig. 5a for the northern and in Fig. 5b for the southern hemispheres.

The emission intensity is about 2 times higher in the southern hemisphere than in the northern, at all local times considered. This confirms the results obtained with OMEGA observations during the same MY (Altieri et al., 2009). Moreover, an increase of the intensity is observed after the morning terminator, while the region at 5-6 local time is the least intense. Because of the observing geometry, no clear indications about the altitude of the emission can be derived.

Two regions on the Mars night side were identified in the available data (see Table 2 for the local time and latitude regions). One of them refers to a local time well after the dusk terminator, hence we are quite confident that the observed emission at $1.27 \mu \mathrm{m}$ is produced through the nightglow mechanism (reaction b). After the spectrum conversion into Rayleigh units and the continuum subtraction, the mean spectrum of the selected region at 2024 LT clearly shows an emission in the region $1.24-1.31 \mu \mathrm{m}$ (Fig. 2b).

Despite the poor spatial resolution of the available data, an indication of the nightglow peak altitude can be provided (Fig. 6). 
Table 2

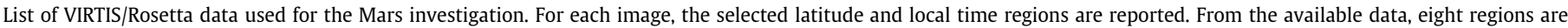

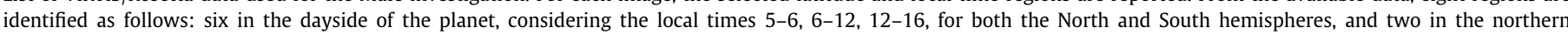
hemisphere for the local times 18-20, 20-24.

\begin{tabular}{|c|c|c|c|c|c|}
\hline Image name & LT 5-6 & LT 6-12 & LT $12-16$ & LT $18-20$ & LT $20-24$ \\
\hline I1_00130961622 & & $68^{\circ} \mathrm{S}-85^{\circ} \mathrm{S}$ & $68^{\circ} \mathrm{S}-85^{\circ} \mathrm{N}$ & & \\
\hline \multirow{2}{*}{ I1_00130962500 } & $42^{\circ} \mathrm{S}$ & $84-86^{\circ} \mathrm{N}$ & $80^{\circ} \mathrm{S}$ & & \\
\hline & & & $70^{\circ} \mathrm{N}$ & & \\
\hline \multirow[t]{2}{*}{ I1_00130963310 } & & $80^{\circ} \mathrm{N}-87^{\circ} \mathrm{N}$ & $70^{\circ} \mathrm{S}-90^{\circ} \mathrm{S}$ & & \\
\hline & & & $0^{\circ} \mathrm{N}-6^{\circ} \mathrm{N}$ & & \\
\hline \multirow[t]{2}{*}{ I1_00130964121 } & & $69^{\circ} \mathrm{S}-88^{\circ} \mathrm{S}$ & $65^{\circ} \mathrm{N}$ & & \\
\hline & & $80^{\circ} \mathrm{N}-81^{\circ} \mathrm{N}$ & & & \\
\hline I1_00130964930 & & $83^{\circ} \mathrm{N}-87^{\circ} \mathrm{N}$ & $51^{\circ} \mathrm{N}-72^{\circ} \mathrm{N}$ & & \\
\hline \multirow[t]{2}{*}{ I1_00130965741 } & $24^{\circ} \mathrm{N}-14^{\circ} \mathrm{N}$ & $14^{\circ} \mathrm{N}-87^{\circ} \mathrm{S}$ & $71^{\circ} \mathrm{S}-77^{\circ} \mathrm{S}$ & & \\
\hline & & $77^{\circ} \mathrm{N}-87^{\circ} \mathrm{N}$ & $48^{\circ} \mathrm{N}-85^{\circ} \mathrm{N}$ & & \\
\hline \multirow[t]{2}{*}{ I1_00130966610 } & $13^{\circ} \mathrm{N}-23^{\circ} \mathrm{N}$ & $5^{\circ} \mathrm{N}-11^{\circ} \mathrm{N}$ & $51^{\circ} \mathrm{S}-88^{\circ} \mathrm{S}$ & & \\
\hline & & $76^{\circ} \mathrm{N}-87^{\circ} \mathrm{N}$ & $43^{\circ} \mathrm{N}-74^{\circ} \mathrm{N}$ & & \\
\hline \multirow[t]{2}{*}{ I1_00130967541 } & $66^{\circ} \mathrm{S}-75^{\circ} \mathrm{S}$ & $77^{\circ} \mathrm{S}-81^{\circ} \mathrm{S}$ & $12^{\circ} \mathrm{N}-16^{\circ} \mathrm{S}$ & & \\
\hline & & $73^{\circ} \mathrm{N}-87^{\circ} \mathrm{N}$ & $55^{\circ} \mathrm{N}-71^{\circ} \mathrm{N}$ & & \\
\hline I1_00130972701 & & $81^{\circ} \mathrm{N}-83^{\circ} \mathrm{N}$ & & & \\
\hline I1_00130973361 & & & $65^{\circ} \mathrm{N}-75^{\circ} \mathrm{N}$ & & \\
\hline I1_00130974021 & $3^{\circ} \mathrm{N}-18^{\circ} \mathrm{N}$ & $77^{\circ} \mathrm{S}-88^{\circ} \mathrm{S}$ & $71^{\circ} \mathrm{S}-75^{\circ} \mathrm{S}$ & & \\
\hline \multirow[t]{2}{*}{ I1_00130974741 } & $7^{\circ} \mathrm{N}-9^{\circ} \mathrm{N}$ & $72^{\circ} \mathrm{S}-80^{\circ} \mathrm{S}$ & $13^{\circ} \mathrm{S}-19^{\circ} \mathrm{S}$ & & \\
\hline & & $82^{\circ} \mathrm{N}-86^{\circ} \mathrm{N}$ & $64^{\circ} \mathrm{N}-85^{\circ} \mathrm{N}$ & & \\
\hline I1_00131004789 & & & & $65^{\circ} \mathrm{N}-69^{\circ} \mathrm{N}$ & \\
\hline I1_00131006589 & & & & $67^{\circ} \mathrm{N}-70^{\circ} \mathrm{N}$ & \\
\hline I1_00131007789 & & & & $65^{\circ} \mathrm{N}-77^{\circ} \mathrm{N}$ & $78^{\circ} \mathrm{N}-82^{\circ} \mathrm{N}$ \\
\hline
\end{tabular}
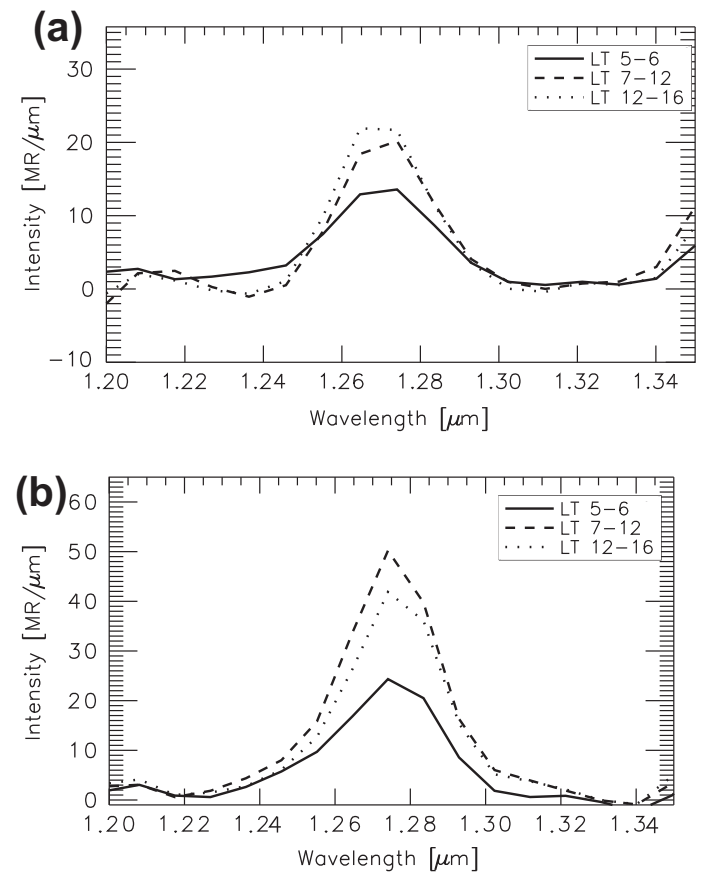

Fig. 5. (a) $\mathrm{O}_{2}$ dayglow spectrum of the northern hemisphere of Mars at selected local times. (b) The same for the southern hemisphere.

In the figure, measured radiance versus altitude of the line of sight in $\mathrm{km}$ is represented. The altitude range considered is divided into bins $30-\mathrm{km}$ wide. The intensity is then averaged in each altitude bin. The resulting peak altitude is $45 \pm 15 \mathrm{~km}$, in agreement with both OMEGA and SPICAM observations (Bertaux et al., 2012; Fedorova et al., 2012). The same result is obtained by fitting the VIRTIS data with a Gaussian distribution (gray curve in Fig. 6). On the other hand, in the shown image, the distance of the spacecraft from the planet is on average about $165,000 \mathrm{~km}$, hence the spatial resolution is about $40 \mathrm{~km}$ per pixel. By fitting the data with a Gaussian profile, we can also infer a peak intensity equal to

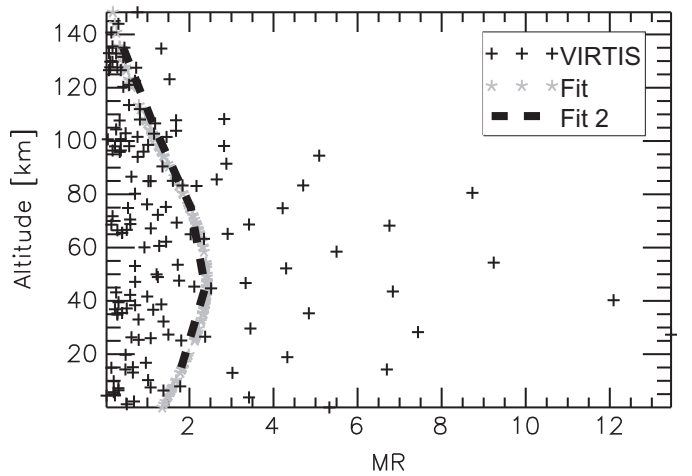

Fig. 6. Tangent profile of the $\mathrm{O}_{2}$ nightglow emission in the Mars atmosphere. The image shows the nightglow emission versus tangent altitude. To derive the profile, we divided the altitude range into $30-\mathrm{km}$ bins and averaged the intensity of each bin (dotted black curve). The peak is found on average at $45 \pm 15 \mathrm{~km}$, and the emission intensity is $2.4 \mathrm{MR}$ at peak. The same result is found by fitting the data with a Gaussian curve (gray curve)

2.4 MR, which corresponds to $0.13 \mathrm{MR}$ at the nadir, assuming a factor of 18 to convert from the limb to nadir view. This conversion factor is obtained by assuming $80 \mathrm{~km}$ as the effective limb thickness (i.e. twice the spatial resolution of 1 pixel) and $40 \mathrm{~km}$ for the altitude at the limb. However, it should be noted that the uncertainty associated to this value is strongly affected by the low spatial resolution of the image cube considered.

Previous observations of the $\mathrm{O}_{2}$ nightglow in the Mars' atmosphere were obtained by OMEGA (Bertaux et al., 2012) and SPICAM (Fedorova et al., 2012) experiments on board Mars Express, and by CRISM/MRO (Clancy et al., 2012). The LMD general circulation model was run to derive a zonally averaged $\mathrm{O}_{2}\left(\mathrm{a}^{1} \Delta_{\mathrm{g}}\right)$ vertical emission produced by the 3-body recombination mechanism (Bertaux et al., 2012). It predicts the distribution of the emission with respect to latitude and solar longitude at midnight. In order to interpret our nightglow detection, we superimposed VIRTIS observation to the modeled $\mathrm{O}_{2}$ intensity distribution (Fig. 7), taken from Bertaux et al. (2012). It is displayed in Fig. 7 with a red star. OMEGA positive detections of the $\mathrm{O}_{2}$ nightglow are marked with a pink star 
in the same plane, while OMEGA data where the emission is not present are shown with a white star.

Considering the solar longitude and the latitude of our observation, the predicted intensity of the nightglow emission is in the range $0.6-1 \mathrm{MR}$. This value is widely different from the one measured in the VIRTIS image. This may be attributed to the high uncertainty of the measurement, to a real day-to-day variability in the martian atmosphere, or to an uncertainty in the 3-body recombination model not well known at the low temperatures of the martian atmosphere (Bertaux et al., 2012).

\subsection{Venus observed by VIRTIS/Venus Express}

In this Section, we review the results about the airglow detection in the Venus atmosphere, obtained using experiments on board Venus Express and also from ground. After the Venus Express orbit insertion, a great improvement in the nightglow observations of Venus was obtained. Apart from the minor species detection, reviewed in Section 1, several results about the atmospheric circulation (Hueso et al., 2008) and composition (Marcq et al., 2008; Irwin et al., 2008; Cottini et al., 2012; Yung et al., 2009), winds (Peralta et al., 2008; Piccialli et al., 2008; Moissl et al., 2009; Hueso et al., 2012), wave activity (Peralta et al., 2012), the thermal structure (Tellmann et al., 2009; Grassi et al., 2008, 2010; Migliorini et al., 2012), and clouds (Barstow et al., 2012; Titov et al., 2012) have been published so far. Concerning the nightglow, the (0-0) and (0-1) $\mathrm{O}_{2}$ emission bands of the $\left(\mathrm{a}^{1} \Delta_{\mathrm{g}}-\mathrm{X}^{3} \sum_{\mathrm{g}}^{-}\right)$at $1.27 \mu \mathrm{m}$ and $1.58 \mu \mathrm{m}$, as well as the Herzberg II and the Chamberlain systems in the $0.3-0.7 \mu \mathrm{m}$ spectral range were simultaneously detected by VIRTIS (Piccioni et al., 2009; García-Muñoz et al., 2009a; Migliorini et al., 2013). A comparison between the $\mathrm{O}_{2}$ emissions in the visible and infrared ranges observed simultaneously shows that there is a slight but significant difference in the peak altitude location of the emissions due to the Herzberg II, Chamberlain and Infrared Atmospheric bands (Migliorini et al., 2013). This behavior is explained in terms of different efficiency of collisional quenching by $\mathrm{CO}_{2}$ and $\mathrm{O}$ on the $\mathrm{O}_{2}$ metastable states, as reported in Gérard et al. (2013).

Table 3 summarizes the dayglow and nightglow intensities for $\mathrm{O}_{2}$ emission bands of the terrestrial planets.

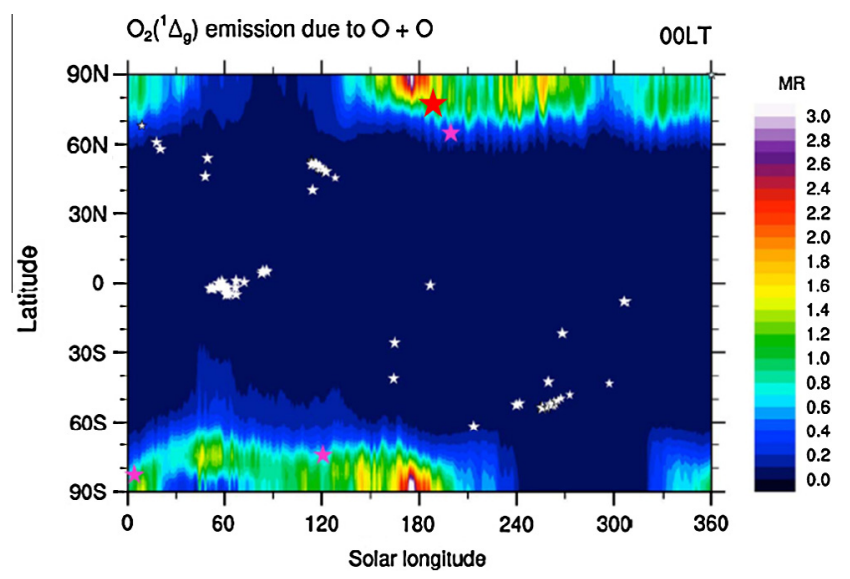

Fig. 7. Nightglow intensity distribution calculated with the LMD general circulation model (Bertaux et al., 2012). The red star indicates the position of our nightglow detection, in terms of latitude and season indicated by the solar longitude $L_{s}$. The model predicts a $0.6-1$ MR intensity for our detection, which is higher than the actual intensity observed with VIRTIS $(130 \mathrm{kR})$. The white and pink stars, in the same plane, refer to OMEGA/Mars Express observations which report a negative or positive $\mathrm{O}_{2}$ nightglow detection, respectively.

\section{Conclusions}

In the present work we compare the oxygen and hydroxyl airglow emissions observed in Earth, Venus, and Mars data returned by the VIRTIS instruments. In particular, we reviewed the results obtained using Venus Express data about the nightglow of $\mathrm{O}_{2}$ and $\mathrm{OH}$ in the visible and infrared, and we present data acquired with the VIRTIS experiment on board Rosetta mission, during the Earth and Mars fly-bys, never published so far.

As a general remark we point out the unique opportunity we had because for the three terrestrial planets, the same type of instrument was used to perform observations suitable for the airglow measurements. In principle, this eases the comparison of the results. Moreover, the VIRTIS instruments on board Venus Express and Rosetta allow one to simultaneously sound the visible and infrared spectral ranges, which is possible neither with Earthbased instrumentation nor with other space-borne instruments operating on current planetary missions.

The observations described in the present work can be summarized as follows:

1. For the Earth, the $\mathrm{O}_{2}$ dayglow emission at $1.27 \mu \mathrm{m}$ is investigated by considering 5-deg bins of latitude, reporting a slight variability with this parameter. The nightglow is also observed but, due to pointing restrictions, it is limited to altitudes higher than $87 \mathrm{~km}$. Hence it is not possible to derive the altitude and intensity of the emission peaks. The mean spectrum, showing $\mathrm{O}_{2}$ and $\mathrm{OH}(v=1,2)$ signatures, is used to refine the VIRTIS spectral calibration, by means of a high resolution $\mathrm{OH}$ spectrum, acquired with ESO/ISAAC spectrometer. A major result is that to fit the VIRTIS spectrum with the spectral calibration a mean shift of $11.5 \mathrm{~nm}$ towards shorter wavelengths is required. Simultaneous observations in the visible and infrared spectral ranges allowed us to derive a band ratio equal to $80-100$ for the $\mathrm{O}_{2}(0-0)$ IR Atmospheric band and the Atmospheric band. Although the same comparison is in principle possible for the venusian case by means of the VIRTIS/Venus Express instrument, the $\mathrm{O}_{2}\left(0_{-}-0\right)$ Atmospheric band at $760 \mathrm{~nm}$ has not been detected so far in the Venus atmosphere. The estimated upper limit of this emission along the vertical direction is $40 \mathrm{R}$, four times less than the upper limit estimated by Krasnopolsky (2011).

2. Dayglow and nightglow $\mathrm{O}_{2}$ measurements are reported for Mars. The observations by VIRTIS/Rosetta confirm the major findings for the $\mathrm{O}_{2}$ dayglow, and sign the first $\mathrm{O}_{2}$ nightglow detection with this instrument in the martian atmosphere, reporting a value of $0.13 \mathrm{MR}$ in the vertical direction. The observation places well in the latitude-longi-

Table 3

Oxygen airglow in the terrestrial planets.

\begin{tabular}{llll}
\hline & Venus & Earth & Mars \\
\hline $\mathrm{O}_{2}\left(\mathrm{~b}^{1} \sum_{\mathrm{g}}^{+}-X^{3} \sum_{\mathrm{g}}^{-}\right)$Day & - & $100 \mathrm{kR}^{\mathrm{a}}$ & - \\
$\mathrm{O}_{2}\left(\mathrm{~b}^{1} \sum_{\mathrm{g}}^{+}-X^{3} \sum_{\mathrm{g}}^{-}\right)$Night & $40 \mathrm{R}^{\mathrm{b}}$ & $4 \mathrm{kR}^{\mathrm{e}}$ & - \\
$\mathrm{O}_{2}\left(\mathrm{a}^{1} \Delta_{\mathrm{g}}-X^{3} \sum_{\mathrm{g}}^{-}\right)$Day & $1.5 \mathrm{MR}^{\mathrm{c}}$ & $1.5 \mathrm{MR}^{\mathrm{f}, \mathrm{g}}$ & $0.9 \mathrm{MR}^{\mathrm{f}}$ \\
$\mathrm{O}_{2}\left(\mathrm{a}^{1} \Delta_{\mathrm{g}}-X^{3} \sum_{\mathrm{g}}^{-}\right)$Night & $0.52 \mathrm{MR}^{\mathrm{d}}$ & $80 \mathrm{kR}^{\mathrm{e}}$ & $0.130 \mathrm{MR}^{\mathrm{f}}$ \\
\hline
\end{tabular}

a Rikitake (1990).

b Upper limit from VIRTIS/VEx data.

c From Connes et al. (1979).

d From Piccioni et al. (2009).

e Greer et al. (1986).

f This work.

$\mathrm{g}$ The value is obtained considering the gain factor to convert from limb to Nadir view equal to 50 . 
tude intensity distribution, predicted by the LMD general circulation model. Simultaneous observations of the day and night airglow were compared in this investigation.

Finally and importantly, the analysis of VIRTIS/Rosetta data acquired during the fly-bys mission phases allows one to further improve the knowledge of the instrument's response. We have also demonstrated that this analysis is worth to fine tune the spectral calibration of the instrument in view of the upcoming salient phase of the mission, devoted to the investigation of comet $67 \mathrm{P} /$ Churyumov-Gerasimenko.

\section{Acknowledgments}

The authors wish to thank ESA, ASI, CNES and all the national space agencies which support Venus-Express and Rosetta missions (Grant: ASI-INAF I/050/10/0 and ASI-INAF I/062/08/0). JCG was supported by the PRODEX program of the European Space Agency, managed in collaboration with the Belgian Federal Science Policy Office.

\section{Appendix A. VIRTIS-M-IR spectral calibration update}

In this appendix we discuss about two instrumental effects, never discussed before, affecting the spectral response of VIRTIS$\mathrm{M} / \mathrm{IR}$ channel and therefore influencing the scientific interpretation of the results. The first effect is the non-uniformity of the spectral response along the spectrometer's slit (e.g. the "sample" spatial direction); the second is the drift of the spectral response induced by the thermal load on the instrument mechanical mount.

The VIRTIS-M instrument was characterized on the ground, before the Rosetta launch, using a dedicated setup (Ammannito et al., 2006; Filacchione et al., 2006; Filacchione, 2006). Thanks to a combination of monochromator's spectral scans and absolute spectral source (HgNe lamp) acquired with the optical head in a thermalvacuum chamber and stabilized at the nominal operative temperature (spectrometer's mount at $T=135 \mathrm{~K}$, IR focal plane at $T=80 \mathrm{~K}$ ), the following spectral dispersion law was inferred:

$\lambda_{c}(b)=1000.39+9.44 \cdot b$,

where $b$ is the spectral band index $(0 \leqslant b \leqslant 431), 1000.39 \mathrm{~nm}$ is the wavelength of the first spectral band $(b=0)$ and $9.44 \mathrm{~nm} /$ band is the spectral sampling. Such values are an average response for pixels close to the bore sight ( $110 \leqslant$ sample $\leqslant 140)$.

We know that the accuracy and uniformity of the spectral response of a complex imaging spectrometer like VIRTIS-M result from a compromise: it is necessary to maximize the contribution of the grating's dispersion while reducing the effects of the aberrations caused by optical elements, in particular the astigmatism introduced by the convex grating. As a result, the spectral response of the instrument along different pixels of the field of view is not perfectly constant. We have characterized this effect thanks to the acquisitions of the VIRTIS internal calibration lamps (Filacchione et al., 2006; Filacchione, 2006) that allow us to measure a reproducible reference signal during the different phases of the mission. The internal calibration unit is designed in fact to illuminate uniformly the internal wall of the cover placed at the optical entrance pupil of the system. This solution allows performing relative checks of the instrument's performances. In Fig. A1 is shown a zoom of the IR internal source signal between bands 230-270 (3171.59-3549.19 nm) after having corrected the signal for the corresponding dark current and background. At these wavelengths the intense absorptions by $\mathrm{C}-\mathrm{H}$ aromatics induced by the polystyrene plastic film housed on the lamp aperture are placed (Melchiorri et al., 2003). These features can be used to check the uniformity of the spatial and spectral responses of the spectrometer. Looking at signal image collected by the focal plane, it is evident that the position of the absorptions drifts linearly of about 1.5 bands moving along the slit from low to high samples (inset figure). Therefore the coefficient $1000.39 \mathrm{~nm}$ indicated in equation A.1 and measured on central samples must be corrected in $995.39 \mathrm{~nm}$ at sample $=1$, in $1005.11 \mathrm{~nm}$ at sample 256 and linearly between these two extremes.

For a correct interpretation of the results a second instrumental behavior needs to be considered. We have seen that changes in the temperature of the spectrometer's optical bench cause a shift in the spectral response. This probably happens because the optical bench is stressed and consequently the relative position of the focal plane changes respect to the grating. A similar effect is particularly evident on data taken after the Earth and Mars flybys when the VIRTIS radiator was exposed for a significant time to the thermal emission of the planets causing an increase of the temperature of the optical bench. In Fig. A2 the internal calibration signals extracted at slit center (sample $=128$ ) and towards the two sides of the FoV (sample $=32$ and 224) for the two extreme thermal conditions occurred during the cruise phase are shown: the cold case corresponds to internal calibration sequence I1_00100355472, acquired on 2006-03-07T12:31:36 during one of the Rosetta's passive checkouts (spectrometer's temperature $=134.56 \mathrm{~K}$, FPA's temperature $=86.56 \mathrm{~K}$ ); the warm case matches with sequence I1_00068628676 taken on 2005-0305T07:31:35 during the Rosetta Earth's first flyby (spectrometer's temperature $=144.61 \mathrm{~K}$, FPA's temperature $=88.17 \mathrm{~K}$ ). Starting from $134.56 \mathrm{~K}$, a $10 \mathrm{~K}$ increase of the spectrometer's temperature causes a spectral shift of about 1 spectral band towards longer wavelengths ( $0.1 \mathrm{band} / \mathrm{K})$. This was verified using the position of the diagnostic absorption features introduced by the polystyrene filter in the IR lamp signal.

The VIRTIS-M calibration pipeline, discussed in Filacchione (2006), shall be updated to include the correction of these two

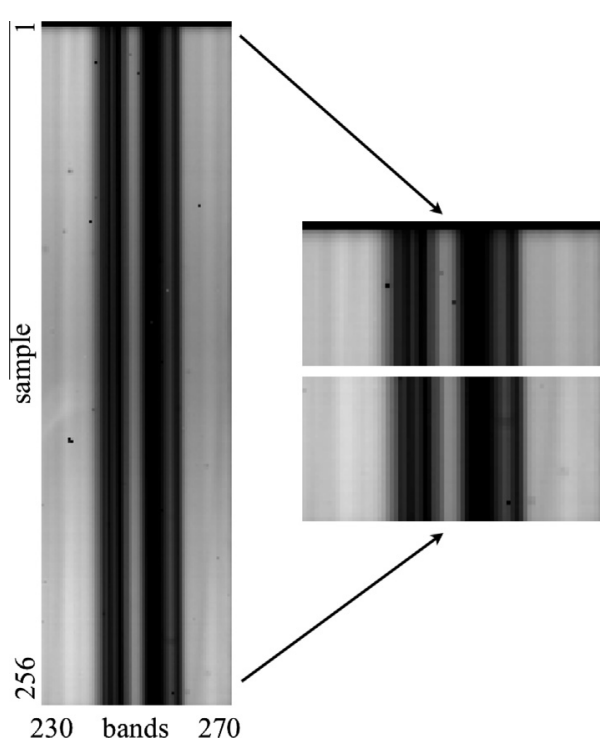

Fig. A1. VIRTIS-M/IR channel acquisition of the internal calibration source (IR lamp equipped with polystyrene filter). Left: resize of the signal on the spectral region between bands $230-270(3171.59-3549.19 \mathrm{~nm})$ where the most intense absorption features of the polystyrene filter can be seen. In this figure the spectral dispersion is along $x$ axis and the spatial along $-y$ axis. Right: the spectral shift between the two edges of the FoV is clearly evident comparing the position of the bands on the two zoomed images: the absorption features are shifted toward longer wavelengths on the bottom image resulting in a linear drift of about 1.5 bands moving along the slit from low to high samples. 


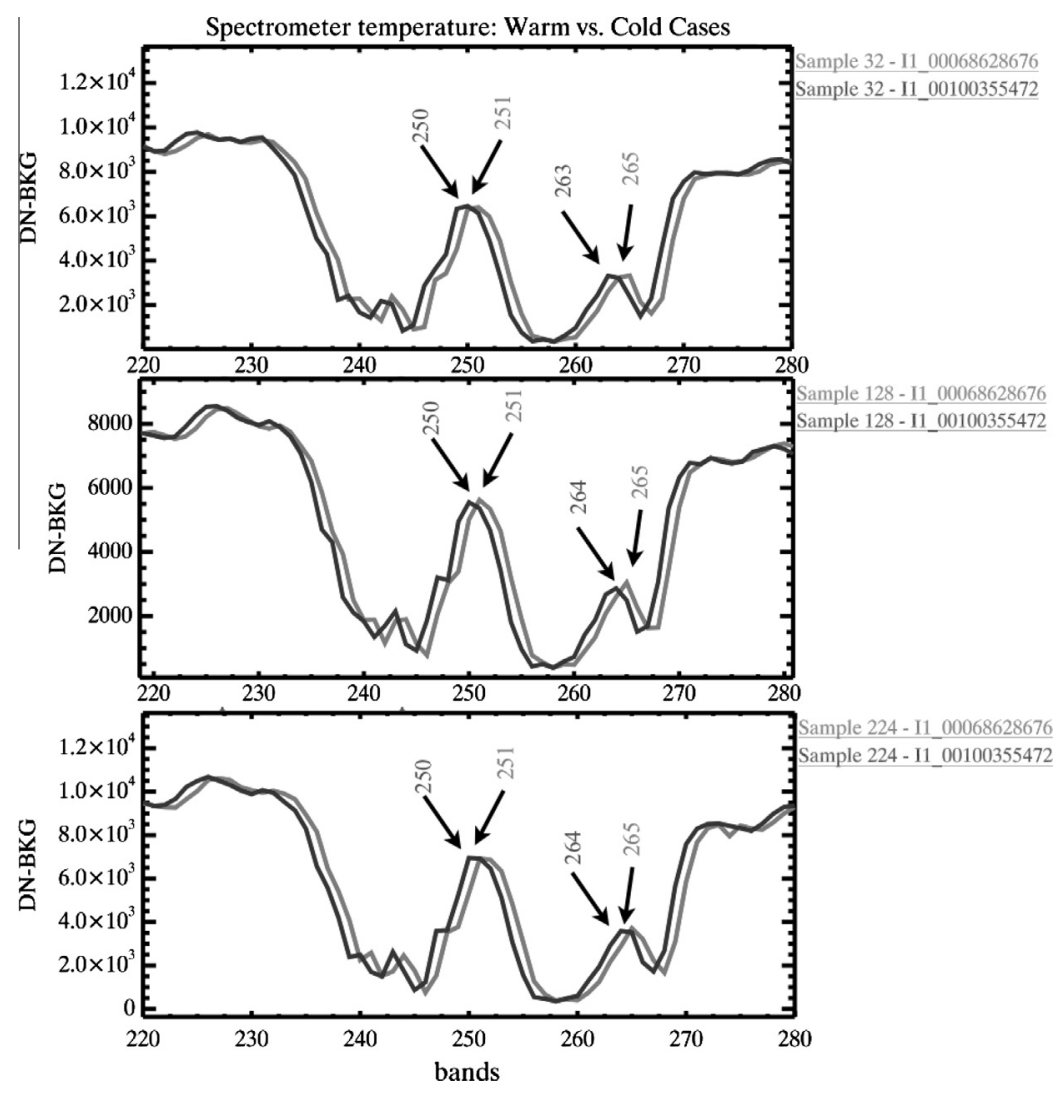

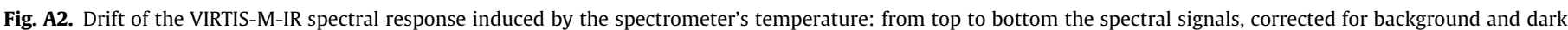

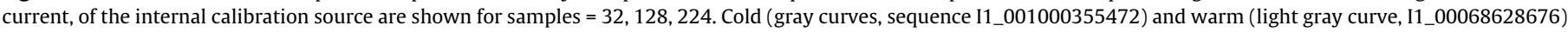

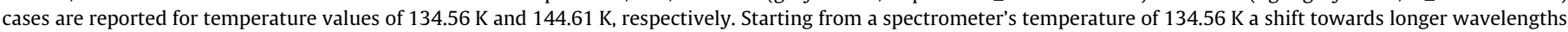
of about 0.1 band $/ \mathrm{K}$ is measured.

additional effects in order to guarantee better results for the upcoming Rosetta phase at comet 67P/Churyumov-Gerasimenko.

\section{References}

Altieri, F. et al., 2009. $\mathrm{O}_{2} 1.27 \mu \mathrm{m}$ maps as derived from OMEGA/MEx data. Icarus 204, 499-511. http://dx.doi.org/10.1016/j-icarus.2009.07.022.

Ammannito, E. et al., 2006. On-ground characterization of Rosetta/VIRTIS-M. I. Spectral and geometrical calibrations. Rev. Sci. Instrum. 77 (9), 093109093109-10.

Bailey, J., Meadows, V.S., Chamberlain, S., Crisp, D., 2008. The temperature of the Venus mesosphere from $\mathrm{O}_{2}\left(\mathrm{a}^{1} \Delta_{\mathrm{g}}\right)$ airglow observations. Icarus 197, 247-259.

Baker, D.J., Stair Jr., A.T., 1988. Rocket measurements of the altitude distributions of the hydroxyl airglow. Phys. Scripta 37, 611-622, ISSN: 0031-8949.

Ball, S.M., Hancock, G., 1995. The relative quantum yield of $\mathrm{O}_{2}\left(\mathrm{a}^{1} \Delta_{\mathrm{g}}\right)$ from photolysis of ozone at 227 K. Geophys. Res. Lett. 22, 1213-1216.

Ball, S.M., Hancock, G., Murphy, I.J., Rayner, S.P., 1993. The relative quantum yields of $\mathrm{O}_{2}\left(\mathrm{a}^{1} \Delta_{\mathrm{g}}\right)$ from photolysis of ozone in the wavelength range $270 \mathrm{~nm}<\lambda<329$ nm. Geophys. Res. Lett. 20, 2063-2066.

Barstow, J.K. et al., 2012. Models of the global cloud structure on Venus derived from Venus Express observations. Icarus 217, 542-560.

Bates, D.R., Nicolet, M., 1950. Atmospheric hydrogen. Publ. Astron. Soc. Pacific 62 (365), 106-110.

Becker, K.H., Groth, W., Schurath, U., 1971. The ratio of the Franck-Condon factors $q(0,0) / q(0,1)$ of the infrared Atmospheric band system of oxygen. Planet. Space Sci. 19, 1009-1010.

Bertaux, J.-L., Gondet, B., Lefèvre, F., Bibring, J.-P., Montmessin, F., 2012. First detection of $\mathrm{O}_{2} 1.27 \mu \mathrm{m}$ nightglow emission at Mars with OMEGA/MEX and comparison with general circulation model predictions. J. Geophys. Res. 117. http://dx.doi.org/10.1029/2011JE003890.

Bougher, S.W., Borucki, W.J., 1994. Venus $\mathrm{O}_{2}$ visible and IR nightglow: Implications for lower thermosphere dynamics and chemistry. J. Geophys. Res. 99, 37593776. http://dx.doi.org/10.1029/93JE03431.

Clancy, R.T. et al., 2012. Extensive MRO CRISM observations of $1.27 \mu \mathrm{m} \mathrm{O}_{2}$ airglow in Mars polar night and their comparison to MRO MCS temperature profiles and LMD GCM simulations. J. Geophys. Res. http://dx.doi.org/10.1029/ 2011JE004018, in press.

Connes, P., Noxon, J.F., Traub, W.A., Carleton, N.P., 1979. O $/ 1$ Delta/emission in the day and night airglow of Venus. Astrophys. J. 233, L29-L32 (Letters to the Editor).
Coradini, A. et al., 2007. Virtis: An imaging spectrometer for the Rosetta mission. Space Sci. Rev. 128, 529-559.

Coradini, A. et al., 2010. Martian atmosphere as observed by VIRTIS-M on Rosetta spacecraft. J. Geophys. Res. 115. http://dx.doi.org/10.1029/2009JE003345.

Coradini, A. et al., 2011. The surface composition and temperature of Asteroid 21 Lutetia as observed by Rosetta/VIRTIS. Science 334, 492-494.

Cottini, V., Ignatiev, N.I., Piccioni, G., Drossart, P., Grassi, D., Markiewicz, W.J., 2012. Water vapor near the cloud tops of Venus from Venus Express/VIRTIS dayside data. Icarus 217, 561-569.

Crisp, D., Meadows, V.S., Bézard, B., de Bergh, C., Maillard, J.-P., Mills, F.P., 1996. Ground-based near-infrared observations of the Venus nightside: $1.27-\mu \mathrm{m}$ $\mathrm{O}_{2}\left(\mathrm{a} \Delta_{\mathrm{g}}\right)$ airglow from the upper atmosphere. J. Geophys. Res. 101 (E2), 45774594.

Evans, W.F.J., Llewellyn, E.J., 1972. Measurements of mesospheric ozone from observations of the $1.27 \mu \mathrm{m}$ band. Radio Sci. 7, 45-50.

Evans, W.F.J., Llewellyn, E.J., Vallance Jones, A., 1972. Altitude distribution of the $\mathrm{O}_{2}\left({ }^{1}\right.$ DELTA $)$ nightglow emission. J. Geophys. Res 77, 4899-4901.

Fedorova, A.A., Korablev, O., Perrier, S., Bertaux, J.-L., Lefèvre, F., Rodin, A., 2006. Observations of the $\mathrm{O}_{2} 1.27 \mu \mathrm{m}$ dayglow by SPICAM IR: Seasonal distribution for first martian year of Mars-Express. J. Geophys. Res. 111, E09S07.

Fedorova, A.A., Lefèvre, F., Guslyakova, S., Korablev, O., Bertaux, J.-L., Montmessin, F., 2012. The $\mathrm{O}_{2}$ nightglow in the martian atmosphere by SPICAM onboard of MarsExpress. Icarus 219, 596-608.

Filacchione, G., 2006. Calibrazioni a terra e prestazioni in volo di spettrometri ad immagine nel visibile e nel vicino infrarosso per l'esplorazione planetaria, $\mathrm{PhD}$ dissertation, Università degli Studi di Napoli Federico II, 316 pages. ftp.iasfroma.inaf.it/gianrico/phd/Filacchione_PHD_2006.pdf (in italian).

Filacchione, G. et al., 2006. On-ground characterization of Rosetta/VIRTIS-M. I. Spatial and radiometric calibrations. Rev. Sci. Instrum. 77, 103-106.

Findlay, F.D., 1969. Relative band intensities in the atmospheric and infrared atmospheric systems of molecular oxygen. Can. J. Phys. 47, 687-691.

García-Muñoz, A., Mills, F.P., Slanger, T.G., Piccioni, G., Drossart, P., 2009a. Visible and near-infrared nightglow of molecular oxygen in the atmosphere of Venus. J. Geophys. Res. 114, E12002. http://dx.doi.org/10.1029/2009JE003447.

García-Muñoz, A., Mills, F.P., Piccioni, G., Drossart, P., 2009b. From the Cover: The near-infrared nitric oxide nightglow in the upper atmosphere of Venus. Proc. Nat. Acad. Sci. USA 106 (4), 985-988.

Geminale, A., Grassi, D., Formisano, V., García-Muñoz, A., Sindoni, G., Giuranna, M., 2012. Interannual Study of the Oxygen Day-Glow in the Martian atmosphere with data of PFS-MeX, EGU General Assembly 2012, held 22-27 April, 2012, in Vienna, Austria, p. 12565. 
Gérard, J.-C. et al., 2008. Distribution of the $\mathrm{O}_{2}$ infrared nightglow observed with VIRTIS on board Venus Express. Geophys. Res. Lett. 35 (2), CiteID L02207.

Gérard, J.C., Saglam, A., Piccioni, G., Drossart, P., Montmessin, F., Bertaux, J.L., 2009. Atomic oxygen distribution in the Venus mesosphere from observations of $\mathrm{O}_{2}$ infrared airglow by VIRTIS-Venus Express. Icarus 199, 264-272.

Gérard, J.-C., Soret, L., Saglam, A., Piccioni, G., Drossart, P., 2010. The distributions of the $\mathrm{OH}$ Meinel and $\mathrm{O}\left(\mathrm{a}^{1} \Delta-\mathrm{X}^{3} \Sigma\right)$ nightglow emissions in the Venus mesosphere based on VIRTIS observations. Adv. Space Res. 45, 1268-1275.

Gérard, J.-C., Soret, L., Piccioni, G., Drossart, P., 2012. Spatial correlation of OH and $\mathrm{O}_{2}$ infrared atmospheric nightglow emissions observed with VIRTIS-M on board Venus Express. Icarus 217, 813-817.

Gérard, J.-C., Soret, L., Migliorini, A., Piccioni, G., 2013. Oxygen nightglow emissions of Venus: Vertical distribution and collisional quenching. Icarus 223, 602-608.

Grassi, D. et al., 2008. Retrieval of air temperature profiles in the venusian mesosphere from VIRTIS-M data: Description and validation of algorithms. J. Geophys. Res. 113, CiteID E00B09.

Grassi, D. et al., 2010. Thermal structure of venusian night-time mesosphere as observed by VIRTIS-Venus Express. J. Geophys. Res. 115, CiteID E09007.

Greer, R.G.H., Llewellyn, E.J., Solheim, B.H., Witt, G., 1981. The excitation of $\mathrm{O}_{2}\left(\mathbf{b}^{1} \sum_{\mathrm{g}}^{+}\right)$in the nightglow. Planet. Space Sci. 29, 383-389.

Greer, R.G.H., Murtagh, D.P., McDade, I.C., Dickinson, P.H.G., Thomas, L., 1986. ETON I: A database pertinent to the study of energy transfer in the oxygen nightglow. Planet. Space Sci. 34, 771-788.

Haslett, J.C., Fehsenfeld, F.C., 1969. Ratio of the $\mathrm{O}_{2}\left({ }^{1} \Delta_{g}-{ }^{3} \sum_{-}^{\mathrm{g}}\right)(0,0),(0,1)$ transitions. J. Geophys. Res. 74, 1878-1879.

Hays, P.B., Kafkalidis, J.F., Skinner, W.R., 2003. A global view of the molecular oxygen night airglow. J. Geophys. Res. 108. http://dx.doi.org/10.1029/2003JD003400.

Heppner, J.P., Meredith, L.H., 1958. Nightglow emission altitudes from rocket measurements. J. Geophys. Res. 63 (1), 51-65.

Hueso, R. et al., 2008. Morphology and dynamics of Venus oxygen airglow from Venus Express/Visible and InfraRed Thermal Imaging Spectrometer observations. J. Geophys. Res. 113, CiteID E00B02.

Hueso, R., Peralta, J., Sánchez-Lavega, A., 2012. Assessing the long-term variability of Venus winds at cloud level from VIRTIS-Venus Express. Icarus 217, 585598.

Irwin, P.G.J. et al., 2008. Spatial variability of carbon monoxide in Venus' mesosphere from Venus Express/Visible and InfraRed Thermal Imaging Spectrometer measurements. J. Geophys. Res. 113, CiteID E00B01.

Krasnopolsky, V.A., 1983. Venus spectroscopy in the 3000-8000 $\mathrm{A}$ region by Veneras 9 and 10. In: Hunten, D.M. et al. (Eds.), Venus. Univ. of Ariz. Press, Tucson, pp. 459-483.

Krasnopolsky, V.A., 2010. Venus night airglow: Ground-based detection of $\mathrm{OH}$, observations of $\mathrm{O}_{2}$ emissions, and photochemical model. Icarus 207, 17-27.

Krasnopolsky, V.A., 2011. Excitation of the oxygen nightglow on the terrestrial planets. Planet. Space Sci. 59, 754-766.

Krasnopolsky, V.A., Krys'ko, A.A., 1976. On the night airglow of the martian atmosphere. Space Res. 16, 1005-1008.

Krupenie, P.H., 1972. The spectrum of molecular oxygen. J. Phys. Chem. Ref. Data 1, 423-534.

Liu, G., Shepherd, G.G., Roble, R.G., 2008. Seasonal variations of the nighttime O $\left({ }^{1} \mathrm{~S}\right)$ and $\mathrm{OH}$ airglow emission rates at mid-to-high latitudes in the context of the large-scale circulation. J. Geophys. Res. 113 (A6), CiteID A06302.

Llewellyn, E.J., Solheim, B.H., 1978. The excitation of the infrared atmospheric oxygen bands in the nightglow. Planet. Space Sci 26, 533-538.

Lopez-Moreno, J.J., Rodrigo, R., Moreno, F., Lopes-Puertas, M., Molina, A., 1987. Altitude distribution of vibrationally excited states of atmospheric hydroxyl at levels $v=2$ and $v=7$. Planet. Space Sci. 35, 1029-1038.

Lowe, R.P., 1960. The high of the hydroxyl airglow, CARDE Tech. Memo. 291/59 PCC D45-95-10-18, Can Armament Res. And Dev. Estab., Valectier, Quebec.

Lowe, R.P., Leblanc, L.M., Gilbert, K.L., 1996. WINDII/UARS observation of twilight behavior of the hydroxyl airglow, at mid-latitude equinox. J. Atmos. Terr. Phys. 58, 1863-1896.

Marcq, E., Bézard, B., Drossart, P., Piccioni, G., Rees, J.M., Henry, F., 2008. A latitudinal survey of $\mathrm{CO}, \mathrm{OCS}, \mathrm{H}_{2} \mathrm{O}$, and $\mathrm{SO}_{2}$ in the lower atmosphere if Venus: Spectroscopic studies using VIRTIS-H. J. Geophys. Res. 113, CiteID E00B07.

McDade, I.C., 1991. The altitude dependence of the $\mathrm{OH}\left(\mathrm{X}^{2} \pi\right)$ vibrational distribution in the nightglow: Some model expectations. Planet. Space Sci. 39, 10491057.

McDade, I.C. et al., 1986. ETON 2: Quenching parameters for the proposed precursor of $\mathrm{O}_{2}\left(\mathrm{~b}^{1} \sum_{\mathrm{g}}^{+}\right)$and $\mathrm{O}\left({ }^{1} \mathrm{~S}\right)$ in the terrestrial nightglow. Planet. Space Sci. 34, 789800.

McDade, I.C., Llewellyn, E.J., Murtagh, D.P., Greer, R.G.H., 1987. ETON 5: Simultaneous rocket measurements of the $\mathrm{OH}$ Meinel $\Delta v=2$ sequence and $(8,3)$ band emission profiles in the nightglow. Planet. Space Sci. 35, 11371147.

Meinel, A.B., 1950. OH emission bands in the spectrum of the night sky. Astrophys. J. $111,555-564$

Melchiorri, R., Piccioni, G., Mazzoni, A., 2003. VIRTIS-M flight lamps. Rev. Sci. Instrum. 74 (8), 3796-3801.

Melo, S.M.L., Lowe, R.P., Russell., J.P., 2000. Double-peaked hydroxyl airglow profiles observed from WINDII/UARS. J. Geophys. Res. 105 (D10), 12397-12403.

Mende, S.B., Swenson, G.R., Geller, S.P., Viereck, R.A., Murad, E., Pike, C.P., 1993. Limb view spectrum of the Earth's airglow. J. Geophys. Res. 98 (A11), 19117 19125.
Migliorini, A., Piccioni, G., Cardesín Moinelo, A., Drossart, P., 2011. Hydroxyl airglow on Venus in comparison with Earth. Planet. Space Sci. 59, 974-980.

Migliorini, A., Grassi, D., Montabone, L., Lebonnois, S., Drossart, P., Piccioni, G., 2012 Investigation of air temperature on the night side of Venus derived from VIRTISH on board Venus-Express. Icarus 217, 640-647.

Migliorini, A., Piccioni, G., Gérard, J.-C., Soret, L., Slanger, T., Politi, R., Snels, M. Drossart, P., Nuccilli, F., 2013. The characteristics of the $\mathrm{O}_{2}$ Herzberg II and chamberlain bands observed with VIRTIS/Venus Express. Icarus 223, 609-614.

Moissl, R. et al., 2009. Venus cloud top winds from tracking UV features in Venus Monitoring Camera images. J. Geophys. Res. 114 (9), CiteID E00B31.

Montmessin, F. et al., 2011. A layer of ozone detected in the nightside upper atmosphere of Venus. Icarus 216, 82-85.

Murtagh, D.P. et al., 1990. An assessment of proposed $\mathrm{O}\left({ }^{1} \mathrm{~S}\right)$ and $\mathrm{O}_{2}\left(\mathrm{~b}^{1} \sum_{g}^{+}\right)$ nightglow excitation parameters. Planet. Space Sci. 38, 43-53.

Noxon, J.F., 1967. Oxygen spectra in dayglow, twilight and during an eclipse. Nature 213, 350-352.

Noxon, J.F., 1972. Aircraft measurements of $\mathrm{O}_{2}\left({ }^{1} \Delta\right)$ emission. Trans. Am. Geophys. Union 53, 456.

Noxon, J.F., 1982. A global study of $\mathrm{O}_{2}\left({ }^{1} \Delta_{\mathrm{g}}\right)$ airglow: Day and twilight. Planet. Space Sci. 30, 545-557.

Ohtsuki, S., Iwagami, N., Sagawa, H., Kasaba, Y., Ueno, M., Imamura, T., 2005 Ground-based observation of the Venus 1.27- $\mu \mathrm{m} \mathrm{O}$ airglow. Adv. Space Res. 36 (11), 2038-2042.

Ohtsuki, S. et al., 2008a. Imaging spectroscopy of the Venus $1.27 \mu \mathrm{m} \mathrm{O} \mathrm{O}_{2}$ airglow with ground-based telescopes. Adv. Space Res. 41, 1375-1380.

Ohtsuki, S. et al., 2008b. Distributions of the Venus 1.27- $\mu \mathrm{m} \mathrm{O}_{2}$ airglow and rotational temperature. Planet. Space Sci. 56, 1391-1398.

Packer, D.M., 1961. Altitudes of the night airglow radiations. Ann. Geophys. 17, 6775.

Peralta, J., Hueso, R., Sánchez-Lavega, A., Piccioni, G., Lanciano, O., Drossart, P., 2008 Characterization of mesoscale gravity waves in the upper and lower clouds of Venus from VEX-VIRTIS images. J. Geophys. Res. 113 (2). CiteID E00B18.

Peralta, J. et al., 2012. Solar migrating atmospheric tides in the winds of the polar region of Venus. Icarus 220, 958-970.

Piccialli, A. et al., 2008. Cyclostrophic winds from the Visible and InfraRed Thermal Imaging Spectrometer temperature sounding: A preliminary analysis. J. Geophys. Res. 113, CiteID E00B11.

Piccioni, G. et al., 2008. First detection of hydroxyl in the atmosphere of Venus. Astron. Astrophys. 483, L29-L33.

Piccioni, G. et al., 2009. Near-IR oxygen nightglow observed by VIRTIS in the Venus upper atmosphere. J. Geophys. Res. 114, E00B38. http://dx.doi.org/10.1029/ 2008JE003133.

Pick, D.R., Llewellyn, E.J., Vallance Jones, A., 1971. Twilight airglow measurements of the $\mathrm{OH}$ and $\mathrm{O}_{2}$ bands by means of balloon-borne instruments. Can. J. Phys. 49, 897-905.

Rikitake, T., 1990. Compendium of Aeronomy. Terra Scientific Publishing Company Tokio, Kluwer Academic Publishers, pp. 364-365.

Rogers, J.W., Murphy, R.E., Stair Jr., A.T., Ulwick, J.C., 1973. Rocket-borne radiometric measurements of the $\mathrm{OH}$ in the auroral zone. J. Geophys. Res. 78, 70237031.

Rousselot, P., Lidman, C., Cuby, J.-G., Moreels, G., Monnet, G., 2000. Night-sky spectral atlas of $\mathrm{OH}$ emission lines in the near-infrared. Astron. Astrophys. 354 $1134-1150$.

Schulz, R., 2009. Rosetta - One comet rendezvous and two asteroids fly-bys. Solar Syst. Res. 43, 343-352.

Schulz, R., Sierks, H., Küppers, M., Accomazzo, A., 2012. Rosetta fly-by at Asteroid (21)Lutetia: An overview. Planet. Space Sci. 66, 2-8.

Shakun, A., Zasova, L.V., Piccioni, G., Drossart, P., Migliorini, A., 2010. Investigation of oxygen $\mathrm{O}_{2}\left(\mathrm{a}^{1} \Delta_{\mathrm{g}}\right)$ emission on the night side of Venus: Nadir data of the VIRTISM experiment of The Venus Express Mission. Cosmic Res. 48, 232-239.

She, C.-Y., Lowe, R.P., 1998. Seasonal temperature variations in the mesopause region at mid-latitude: Comparison of lidar and hydroxyl rotational temperatures using WINDII/UARS heights profiles. J. Atmos. Sol. Terr. Phys. 60, 1573-1583.

Slanger, T.G., Cosby, P.C., Huestis, D.L., Bida, T.A., 2001. Discovery of the atomic oxygen green line in the Venus night airglow. Science 291, 463-465.

Slanger, T.G., Huestis, D.L., Cosby, P.C., Chanover, N.J., Bida, T.A., 2006. The Venus nightglow: Ground-based observations and chemical mechanism of the oxygen airglow. J. Atmos. Chem. 18, 301-317.

Soret, L., Gérard, J.-C., Piccioni, G., Drossart, P., 2010. Venus OH nightglow distribution based on VIRTIS limb observations from Venus Express. Geophys. Res. Lett. 37, CiteID L06805.

Soret, L., Gérard, J.C., Montmessin, F., Piccioni, G., Drossart, P., Bertaux, J.L., 2012a. Atomic oxygen on the Venus nightside: Global distribution deduced from airglow mapping. Icarus 217, 849-855.

Soret, L., Gérard, J.C., Piccioni, G., Drossart, P., 2012b. The OH Venus nightglow spectrum: Intensity and vibrational composition from VIRTIS-Venus Express observations. Planet. Space Sci. 73, 387-396.

Stair Jr., A.T., Sharma, R.D., Nadile, R.M., Baker, D.J., Grieder, W.F., 1985. Observations of limb radiance with cryogenic spectral infrared rocket experiment. J. Geophys. Res. 90, 9763-9775.

Svedhem, H. et al., 2007. Venus Express - The first European mission to Venus Planet. Space Sci. 55, 1636-1652.

Tarasick, D.W., Evans, W.F.J., 1993. A review of the $\mathrm{O}_{2}\left(\mathrm{a}^{1} \Delta_{\mathrm{g}}\right)$ and $\mathrm{O}^{2}\left(\mathrm{~b}^{1} \sum_{\mathrm{g}}^{+}\right)$airglow emissions. Adv. Space Res. 13, 145-148. 
Tellmann, S., Pätzold, M., Häusler, B., Bird, M.K., Tyler, L., 2009. Structure of the Venus neutral atmosphere as observed by the Radio Science experiment VeRa on Venus Express. Geophys. Res. 114, CiteID E00B36.

Titov, D.V. et al., 2012. Morphology of the cloud tops as observed by the Venus Express Monitoring Camera. Icarus 217, 682-701.

Tosi, F. et al., 2010. The light curve of Asteroid 2867 Steins measured by VIRTIS-M during the Rosetta fly-by. Planet. Space Sci. 58, 1066-1076.

Tosi, F. et al., 2012. The light curve of Asteroid 21 Lutetia measured by VIRTIS-M during the Rosetta fly-by. Planet. Space Sci. 66, 9-22.
Vallance Jones, A., Harrison, A.W., 1958. ${ }^{1} \Delta_{g}-{ }^{3} \sum_{g}^{-}$infrared emission band in the twilight airglow spectrum. J. Atmos. Terr. Phys 13, 45-60.

Winick, J.R., Picard, R.H., Sharma, R.D., Nadile, R.M., 1985. Oxygen singlet delta 1.58$\mu \mathrm{m}(0-1)$ limb radiance in the upper stratosphere and lower mesosphere. J. Geophys. Res. 90, 9804-9814.

Yung, Y.L. et al., 2009. Evidence for carbonyl sulfide (OCS) conversion to CO in the lower atmosphere of Venus. J. Geophys. Res., 114, CiteID E00B34. 